\title{
Le "brigand lusitanien" reconsidéré. Analyse du problème de la terre chez Appien
}

\author{
LUC BARAY \\ CNRS - HDR, UMR 6298 ArTeHiS, Dijon / Sens \\ lucbaray@yahoo.fr
}

Recibido: 22 de noviembre de 2014

Aceptado: 29 de enero de 2014

\section{RÉSUMÉ}

L'étude du "brigandage lusitanien" a donné lieu à une importante activité de recherche depuis la fin $\mathrm{du} \mathrm{XIX}^{\mathrm{e}}$ siècle. Pour autant, et malgré une inflexion progressive de l'historiographie moderne vers une approche plus nuancée de l'origine du phénomène, le problème de la terre reste encore aujourd'hui au centre des préoccupations de nombre d'historiens et d'archéologues. À partir d'une discussion serrée des principaux passages de Tite-Live, Diodore et surtout Appien, relatifs à la relation que d'aucuns ont voulu établir entre manque et/ou pauvreté de la terre et développement du brigandage chez les Lusitaniens, il est proposé une critique de l'interprétation socio-économique.

Mots clés: II ${ }^{\mathrm{e}}$ siècle avant J.-C. Brigandage. Lusitaniens. Manque de terres. Pauvreté de la terre.

\section{Review of the "Lusitanian Robbery". Analysis of the Land Problem in Appiens' Work}

\begin{abstract}
The study of the "Lusitanian robbery" led to an important research since the late nineteenth century. Nevertheless, and despite a gradual shift in modern historiography towards a more nuanced approach to the origin of the phenomenon, the problem of land still remains a central concern of many historians and archaeologists. From a close discussion of the main passages of Livy, Diodorus and Appian especially relating to the relationship that some have sought to establish between lack and / or poverty of the land and development of robbery among the Lusitanians, it gives a review of the socio-economic interpretation.
\end{abstract}

Key words: Second century BC. Robbery. Lusitanians. Landlessness. Poverty of the land.

Sommaire: 1. Introduction. 2. Bref rappel historiographique. 3. Tite-Live ou le récit des résistances indigènes. 4. L'affaire de Compléga ou l'émergence du problème du manque de terres dans l'Ibérique d'Appien. 5. Les guerres lusitaniennes d'après l'Ibérique d'Appien (155-139) ou l'omniprésence du brigand. 6. Les raisons du choix du thème de la faim de terres chez Appien. 


\section{Introduction}

Aujourd'hui encore, la vision défendue par certains historiens ou archéologues de la nature des guerres menées par les peuples de l'Hispania contre Rome, au lendemain de la Deuxième Guerre punique, reste très proche, voire identique, à celle que nous a léguée l'historiographie antique. ${ }^{1}$ Le vocabulaire employé, directement hérité des sources antiques, ne fait d'ailleurs presque jamais référence à la guerre, mais au brigandage. Qu'il s'agisse des termes latins praedo et latro ou grec $\lambda \eta \sigma \tau \eta \varsigma^{2},{ }^{2}$ ils renvoient unanimement à l'idée que les luttes armées qui opposèrent certaines populations d'Hispania, et tout particulièrement les Lusitaniens, aux troupes romaines, entre 205 et $133,{ }^{3}$ ressortissent d'opérations de police entreprises par un État à l'égard de populations révoltées ou insoumises. Jusqu'à très récemment, l'historiographie, à la suite des travaux de J. Costa, ${ }^{4}$ A. García y Bellido ${ }^{5}$ et J. Caro Baroja, ${ }^{6}$ avait privilégié une approche unimodale de type socio-économique pour tenter d'expliquer les raisons et l'ampleur du phénomène. Se fondant sur les références des sources antiques au brigandage des Lusitaniens, les modernes y ont vu le résultat d'un déséquilibre interne aux sociétés d'Hispania ayant pour origine une répartition inégale de la propriété foncière entre les mains d'une minorité de nantis au détriment de la masse, qui était obligée de s'adonner au brigandage et à la razzia pour survivre. L'intervention romaine n'aurait du reste fait qu'aggraver une situation dont l'équilibre reposait sur des structures gentilices ayant depuis longtemps montré leur efficacité. De fait, le brigandage aurait connu une plus forte intensité du côté des régions occidentale et septentrionale de la péninsule Ibérique en raison d'un moindre développement économique et politique des populations qui y vivaient, mais aussi parce que ces dernières firent preuve d'une dynamique démographique bien plus forte qu'ailleurs. ${ }^{7}$

Depuis la fin des années 1990 des voix discordantes se sont cependant élevées pour critiquer cette théorie socio-économique, qui n'est d'ailleurs pas totalement abandonnée aujourd'hui. ${ }^{8}$ Car si c'est désormais une approche plus nuancée qui prédomine, elle ne s'est pas pour autant définitivement débarrassée de toutes les apories des théories antérieures, comme je vais tenter de le montrer à travers un bref rappel historiographique. Ce sera également l'occasion d'examiner les termes du problème tels qu'ils apparaissaient en conclusion des travaux des principaux tenants de la

1 J'adresse mes plus sincères remerciements à Sabine Lefebvre et à Pierre Moret qui ont bien voulu relire ce texte et me faire part de leurs remarques.

2 Voir, entre autres, Liv. 28.32.8-9; 34.13.5; 20.3; 21.1; 35.7.2; App., Ib., 68.289; 69.292; 71.301-302; Plu., Mar, 6.2.

3 Toutes les dates du texte, sauf indication contraire, sont à considérer avant J.-C.

4 Costa 1891-1895, XXXIX-LIV.

5 GarCía y Bellido 1945, 547-604, plus particulièrement 554-565.

6 Caro Baroja [1946] 2003, 290-292.

7 García y Bellido 1945, 561-563.

8 Entre autres, SÁnchez Corriendo 1997, 123-154; Gómez Fraile 1999, 503-505; Alarcão 2001, 338342; SÁNCHEZ Moreno 2006, 55-79; contra Richardson 2000, 141 et 150, qui, sans défendre la théorie socioéconomique, va jusqu'à présenter de manière acritique le texte d'Appien. 
théorie socio-économique. ${ }^{9}$ Je poursuivrai par une analyse serrée des textes de TiteLive et d'Appien relatifs aux guerres lusitaniennes. Il s'agira de proposer une approche critique de la théorie socio-économique à travers l'examen des données littéraires ayant trait au problème de la terre. Mon propos s'articule autour de deux questions simples: pourquoi Appien a-t-il identifié à des brigands les Lusitaniens qui luttèrent contre Rome? Pourquoi a-t-il considéré que le problème était avant tout économique (manque de terres et/ou pauvreté liée à une mauvaise répartition de la terre). Ce ne sont pas les causes sociales, économiques et politiques qui amenèrent ces populations à se soulever et à lutter contre Rome qui m'intéressent ici, mais la position d'Appien vis-à-vis d'une situation de conflit qu'il cherche à expliquer. Les causes socioéconomiques et sociopolitiques ne seront donc qu'indirectement abordées.

\section{Bref rappel historiographique}

Pour nombre d'historiens modernes, la conquête de l'Hispania et la période qui la précéda immédiatement auraient été propices à ce qu'ils nomment la décomposition des structures gentilices. ${ }^{10} \mathrm{Ce}$ phénomène aurait obligé les individus lésés, comme le dit M. Salinas de Frías, à former des bandes de rapine et de pillage qui dévastèrent les régions les plus riches, entrant ainsi en conflit ouvert avec le conquérant romain. ${ }^{11}$ C'est ce qui se serait passé notamment en 194 quand les Lusitaniens descendirent jusqu'en Hispania Ulterior pour y constituer un butin. Pour l'auteur, il n'y avait pas d'autre solution pour Rome, si elle voulait dominer la situation, que de contrôler les régions méridionales situées au sud du Tage, "para impedir las incursiones de los pueblos bárbaros de la Meseta septentrional contra las zonas ya romanizadas o que acababan de caer en poder de los romanos", ${ }^{12}$ et de contracter "pactos favorables con los celtíberos tendentes a solucionar el problema del desigual reparto de la tierra, que era la causa principal de la inestabilidad social y política de estos pueblos". ${ }^{13}$ À la fin des guerres lusitaniennes, en 138, toute la Lusitanie orientale était passée sous contrôle romain. M. Salinas de Frías utilise d'ailleurs un vocabulaire bien spécifique de l'idéologie impérialiste romaine auquel il adhère pleinement, quand il dit, en parlant de l'expédition de D. Iunius Brutus contre les Galicines (138), que "Lusitania oriental [...] se hallaba ya pacificada". ${ }^{14}$ Pour l'auteur, les guerres lusitaniennes "no concluyen sólo por la represión enérgica de los generales romanos, sino porque éstos hubieron de acceder también a cosas que eran exigencias del mismo proceso en que ambos contendientes se hallaban implicados, esto es, los repartos de tierra (concesión

\footnotetext{
9 Pour un résumé des différentes théories qui ont été avancées depuis le XIX ${ }^{\mathrm{e}}$ siècle pour expliquer le banditisme hispanique dans l'Antiquité, voir Gozalbes Cravioto 2006, 1-17.

10 Sur la critique du concept d'organisation gentilice, voir BeltrÁn Lloris 1988, 197-237. Sur la critique de l'usage qui a été fait de ce concept pour justifier la paupérisation des sociétés hispaniques et, partant, le banditisme et le mercenariat, voir GómEZ FraILE 1999, 503-505 et 506-507.

11 Salinas de Frías 1982, 32 et 47; dans le même sens, Sayas Abengochea 1988, 706.

12 Salinas de Frías 1982, 33.

13 Salinas de Frías 1982, 34; Santos Yanguas 1981, 355-366; Rubinsohn 1981, 181-204.

14 Salinas de Frías 1982, 35.
} 
de tierras por Cepión a Tautalos, fundación de una colonia de lusitanos en Valentia por D. Bruto..., etc.). Estos repartos poseen una naturaleza ambigua ya que, si bien responden a los intereses y las necesidades de los pueblos indígenas, iban en contra de la organización gentil que regía en los mismos, ya que implicaban la difusión de la propiedad privada en detrimento de la comunal y la identificación progresiva de los individuos con el terruño, lo que con el tiempo llevaría a que la cohesión que prestaban los vínculos de sangre se debilitasen en favor de los que prestaba la coterritorialidad". ${ }^{15}$

Partant en effet du principe que la société vettone, comme du reste la société lusitanienne, était fondée sur une structure tribale, l'auteur considère comme logique le fait qu'il ait pu exister une propriété commune du sol, tandis que le bétail, qui devait constituer la richesse par excellence, relevait au contraire de la sphère privée. Le brigandage trouvait sa source dans un partage inégal de la terre. ${ }^{16}$ L'auteur établit cependant une distinction entre ce type de brigandage né de contradictions internes et celui pratiqué par les populations pauvres, "arriérées", qui s'attaquaient à leurs voisins. ${ }^{17}$ Dans ces conditions, l'importance du brigandage est proportionnelle aux contradictions économiques qui pouvaient exister au sein de chaque société. ${ }^{18}$

Poursuivant son analyse, M. Salinas de Frías indique clairement qu'il considère que le mercenariat, comme le brigandage, prend sa source dans la décomposition du système gentilice. Aux mêmes causes, les mêmes effets, mais orientés cette fois vers des horizons plus vastes et plus lointains. ${ }^{19}$ Fort de ce constat, l'auteur peut dès lors expliquer les raisons qui poussèrent les autorités romaines à redistribuer des terres aux indigènes en échange d'une paix indispensable à la bonne exploitation des ressources locales. ${ }^{20}$

Plus récemment, M. Salinas de Frías a proposé une approche du "brigandage" lusitanien bien plus nuancé, en remettant en cause, avec raison, l'idée selon laquelle ces gens qui faisaient l'objet de tant de mépris de la part des auteurs antiques ne constituaient pas des bandes de brigands, mais de véritables milices civiques. ${ }^{21} \mathrm{In}$ sistant sur l'importance des effectifs mobilisés par les Lusitaniens à différentes occasions, l'auteur en arrive à une deuxième conclusion importante:

la envergadura de estas expediciones y, además, no concuerda bien con una causa exclusivamente socioeconómica para explicar el fenómeno del bandolerismo lusitano. Por un lado, y dado que la finalidad de estas expediciones era, como dicen los autores clásicos, la obtención de botín y, principalmente, de ganados, hay que pensar que los

15 Salinas de Frías 1982, 35.

16 Salinas de Frías 1982, 47.

17 SAlinas de Frías 1982, 47; Domínguez Monedero 1986, 254-255, reprenant à son compte les stéréotypes de l'idéologie antique, défend, à tort, l'idée que c'est l'aisance économique des Vaccéens, fondée sur le collectivisme agraire, qui aurait poussé les Cantabres à les attaquer fréquemment.

18 Salinas de Frías 1982, 47.

19 Salinas de Frías 1982, 48.

20 Salinas de Frías 1982, 48; Sayas Abengochea 1988, 714; contre l'allusion faite par M. Salinas de Frías à l'obligation faite par les Romains aux populations indigènes de s'installer dans les plaines, je renvoie le lecteur à l'étude suggestive de BÉAL 1996, 339-356, plus particulièrement 344-347.

21 Salinas de Frías 2008, 118. 
hombres que participaban en ellas algo de tierra habían de tener, pues si no a su regreso no tendrían dónde apacentar las reses que habían capturado. Por otro lado, si la cifra de desposeídos hubiera sido tan enormemente elevada, en principio hubiera sido posible encontrar algún tipo de oposición interna a la aristocracia e intentos de cambiar de alguna manera las formas o la estructura de la propiedad; pero las fuentes literarias son claras al afirmar que estos hombres no se enfrentaban contra la sociedad que los colocaba en aquella posición, sino que atacaban a los pueblos vecinos. ${ }^{22}$

En réalité, l'auteur procède à une réorientation à $90^{\circ}$ de son approche du "banditisme" lusitanien, par rapport à la teneur de ses travaux antérieurs. Ne cherchant plus à trouver au sein même des sociétés lusitaniennes les causes socio-économiques de ce fameux banditisme, il tente d'y remédier en rabattant le problème sur la nécessité qu'avaient les Lusitaniens à faire du butin en attaquant leurs voisins, et ce, une fois de plus, en parfaite conformité avec la teneur du discours des auteurs antiques. En définitive, M. Salinas de Frías en revient toujours aux causes socio-économiques pour tenter d'expliquer ce phénomène de grande ampleur qui a tant marqué les esprits des anciens.

Son interprétation du texte de Strabon (3.3.5) relatif aux causes du banditisme lusitanien reste une nouvelle fois attachée à l'explication interne, c'est-à-dire à l'explication qui proviendrait soit d'un mode de fonctionnement propre aux sociétés lusitaniennes (morale de compétition aristocratique et mode de vie "héroïque"), soit à des dysfonctionnments au sein même de ces sociétés. ${ }^{23}$ L'auteur ne cherche pas à établir un lien de cause à effet autre que socio-économique entre l'ampleur de l'activité militaire des Lusitaniens et l'irrésistible progression de l'impérialisme romain. Tout au plus l'auteur accepte de voir dans la présence de l'impérialisme romain "un estímulo de esta actividad militar". ${ }^{24}$

La position de M. Salinas de Frías n’est pas isolée. Bien au contraire, il appartient à ce qu'il convient de nommer la communis opinio telle qu'elle avait court dans l'historiographie espagnole antérieure aux années 2000. ${ }^{25}$ Cette dernière considérait en effet que la cause des guerres que menèrent les légions romaines en Hispania tenait uniquement à la pauvreté des populations indigènes qui en étaient réduites à piller pour survivre. L'inégalité du partage des ressources et l'âpreté d'une partie du pays auraient créé les conditions nécessaires à l'émergence du brigandage et partant du mercenariat. Pour N. Santos Yanguas et M. del Pilar Montero Honorato, par exemple, l'enrôlement comme mercenaires aurait constitué, pour les populations originaires de zones économiquement pauvres et reculées connaissant une forte natalité, la solution la plus simple pour atteindre une position pouvant représenter une avancée du point de vue du statut socio-économique. ${ }^{26}$

22 SALINAS de Frías 2008, 118.

23 SALinas de Frías 2008, 118-119.

24 Salinas de Frías 2008, 119.

25 Pour une approche critique de l'historiographie portant sur les rapports qu'entretinrent les peuples indigènes de la péninsule Ibérique et Rome, voir GARCía Quintela 1990, 181-210; ID. 1991, 61-99.

26 Santos Yanguas - Montero Honorato 1982, 8-9. Sur la relation univoque établie par les modernes entre la pauvreté du pays et le développement du mercenariat hispanique, voir, entre autres, GARCíA Y BELLIDO 1945, 561-563. 
Conformément à l'idéologie des auteurs gréco-latins, la solution à cette situation de crise ne pouvait provenir que de la distribution de terres, seul moyen de résoudre le problème de la pauvreté dont semblait souffrir la grande majorité des Hispani. C'est donc tout naturellement que la fin des guerres lusitaniennes fut suivie de répartitions de terres. ${ }^{27} \mathrm{Il}$ faut croire que les distributions postérieures furent toutefois insuffisantes puisque, malgré les succès romains contre les Lusitaniens en Ulterior, P. Cornelio Scipion Nasica dut se résoudre à les combattre de nouveau en 94, ce qui, selon J. M. Blázquez, "indica que el problema social de este pueblo no es había resuelto" ${ }^{28}$ Pour M. Pastor Muñoz, par exemple, le système aboutit en toute logique à l'émergence du mercenariat. ${ }^{29}$ De retour chez eux après la Deuxième Guerre punique ou dans l'impossibilité, pour ceux qui n'avaient pas pu partir, de s'enrôler comme mercenaires, les Lusitaniens, selon l'auteur, n'ont d'autre solution pour survivre que de se lancer dans le brigandage et dans les actions de pillage contre les territoires déjà sous contrôle romain. C'est la raison pour laquelle la conclusion des guerres lusitaniennes fut marquée, selon J. J. Sayas Abengochea, ${ }^{30}$ par des distributions de terres, c'est-à-dire par la mise en application de ce que l'auteur nomme une "política realista romana". M. Vallejo Girvés considère pour sa part que parmi les actions mises en place par Rome pour combattre le brigandage, il y a "del ofrecimiento de los medios precisos para llevar una existencia alejada del robo y el saqueo, esto es tierra explotable". ${ }^{31}$ L. A. García Moreno a mis l'accent sur les bouleversements occasionnés par la conquête romaine au mode de vie pastoralo-nomade traditionnel des Hispani. Reprenant à son compte la typologie des révoltes mise au point par S. L. Dyson, ${ }^{32}$ García Moreno a tenté d'expliquer le brigandage lusitanien en amalgamant en un même modèle explicatif les mouvements de révolte de type "nativiste" / "millénariste" / "indigéniste", de société de frontière ou de bandit social. Selon l'auteur, l'occupation romaine aurait provoqué la création de zones frontières séparant les sociétés indigènes sous contrôle romain et celles pas encore soumises. Au sein des premières, l'aristocratie aurait poussé le peuple à la résistance contre l'impérialisme romain, inquiète qu'elle aurait été de voir les bases de son pouvoir remises en cause par le processus colonisateur ("mouvement indigéniste"), tandis que dans les zones de frontière, à l'instar de ce qui s'est passé au XIX ${ }^{\mathrm{e}}$ siècle en Amérique du Nord, auraient émergé et se seraient développés des groupes de marginaux caractérisés par une sorte de syncrétisme culturel original mêlant des individus provenant indistinctement des communautés indigènes et des colonisateurs. Il se serait ainsi créé une zone de tensions changeantes dans laquelle s'opposèrent les modes de vie de la société indigène extérieure (nomadisme pastoral et chasse) et celle des colonisateurs (sédentarisme des pionniers). À ces changements s'ajouta la figure charismatique du "bandit social", dont Viriathe fut le plus représentatif. Meneur d'hommes, le bandit

27 BLÁzQuez 1974, 214.

28 BLÁzQuEz 1974, 215.

29 Pastor Muñoz 2008, 42; Miguel y Ayala 2002, 533.

30 Sayas Abengochea 1988, 713.

31 VAllejo Girvés 1994, 172.

32 Dyson 1975, 138-175; ID. 1985, 199-236. 
social prend la tête du mouvement de résistance et mène une lutte acharnée contre les colonisateurs. ${ }^{33}$ Tous ces phénomènes viendront se greffer sur les tensions, existantes au sein même des communautés indigènes, que la conquête romaine allait exacerber et altérer. Car, pour L. A. García Moreno, suivant en cela les propositions de A. García y Bellido, la cause essentielle de la grande effervescence que l'on constate dans les sociétés implantées au-delà de la zone de frontière d'où proviennent les guerriers pratiquant les razzias dans la partie soumise à Rome, est "la natural falta de tierras originada en su particular economía silvo-pastoril preferente" ${ }^{34}$ Cette dernière étant "debía verse ahora agravada por un creciente proceso de diferenciación social y económica en beneficio de los representantes de la aristocracia tribal; proceso que en gran medida debía originarse en otro de aculturación espontáneo a partir de la zona fronteriza de contacto con la provincia romana". ${ }^{35}$ Dans tous les cas, L. A. García Moreno reconnaît au manque de terre un poids déterminant dans l'origine du brigandage lusitanien. ${ }^{36}$ D'ailleurs, il est symptomatique de constater qu'à aucun moment l'auteur ne remet en cause l'idée même du brigandage lusitanien, acceptant de manière tacite l'interpretatio Romana et Graeca.

Or, comme je vais tenter de le montrer, pour Tite-Live il n'y a pas eu de problème lié à la possession de la terre. Si les indigènes combattent les légions de Rome, c'est, au-delà de la dimension à la fois culturelle et idéologique de la guerre chez les Hispa$n i$, parce qu'ils refusent tout simplement de se soumettre. Le résumé des opérations militaires des années 194-190 et l'analyse comparative qu'il est possible d'établir entre le texte de Tite-Live et celui d'Appien sont sur ce point particulièrement éloquentes et riches d'enseignements. En effet, la vision que Tite-Live nous a laissée des guerres qui se déroulèrent dans la péninsule paraît bien plus proche de celle de Polybe qui, au contraire d'Appien, ne parle pas de brigandage, mais insiste sur la férocité guerrière des Hispani.

\section{Tite-Live ou le récit des résistances indigènes}

La guerre qui commence au début de l'été 205 entre Rome et les Hispani, c'est-à-dire quelques mois seulement après l'effondrement de la puissance carthaginoise et le départ des dernières troupes puniques de la péninsule Ibérique (206), est une guerre de conquête du côté des Romains, de résistance du côté des Hispani. ${ }^{37} \mathrm{C}$ 'est dans ce sens qu'il convient de la comprendre si l'on ne veut pas tomber dans les pièges de l'interpretatio Romana.

Pour Tite-Live, il n'y a aucun doute que la cause de ce soulèvement, comme du reste de ceux qui suivront dans les années à venir, est à rechercher dans la volonté des

33 García Moreno 1988, 87.

34 García Moreno 1988, 94.

35 García Moreno 1988, 94.

36 García Moreno 1988, 95-97.

37 Sur le contexte d'intervention des armées romaines en Hispani, voir CADIOU 2008, plus particulièrement 27-83. Pour un résumé des actions menées par Indibilis et son frère Mandonius, voir FrançoIs 2003, 3, n. 16. 
Hispani de ne pas permettre à Rome d'établir son emprise. Alors que cette dernière considérait que les territoires d'où elle avait chassé les Carthaginois lui appartenaient par droit de conquête, les Hispani, de leur côté, considéraient venu le moment de se débarrasser des Romains qu'ils avaient soutenus dans la lutte commune contre les Puniques. Le vocabulaire utilisé par Tite-Live dès le début de sa narration illustre parfaitement l'opposition qui se fit jour très rapidement entre ces deux appréciations différentes de la situation politique qui faisait suite au départ des Carthaginois. La piètre qualité des généraux et des troupes laissés sur place, ${ }^{38}$ comme la mention du territoire des Ausetani qui aurait été soi-disant pacifié (agrum Ausetanum hostico tamquam pacato clementer), ${ }^{39}$ sont autant d'allusions à une conquête qui ne dit pas son nom et qui se trouve prise au dépourvu face à une situation qui lui échappe. La défaite d'Indibilis et la mort de son frère Mandonius et des autres chefs qui participèrent de près ou de loin au soulèvement de 205 ne résolurent pas pour autant le problème de l'occupation militaire romaine et de la soumission des Hispani. Il ne s'agissait que d'une paix armée. En attendant des jours meilleurs, les Hispani acceptèrent, devant la menace d'une intervention militaire, de se soumettre et de payer un tribut double de celui dont ils avaient dû s'acquitter l'année précédente. En parfaite concordance avec l'idéologie colonialiste, Tite-Live précise que Rome leur "rendit la paix". ${ }^{40}$

La suite des évènements montre à quel point l'occupation de l'Hispania représentait pour Rome un moyen de s'enrichir et pour ses généraux un moyen de se faire un nom et d'en rapporter gloire et richesses. ${ }^{41}$ L'ovation accordée au proconsul $L$. Cornelius Lentullus, à son retour d'Espagne, au cours de l'été 200, en est la parfaite illustration..$^{42}$ Outre la gloire qu'il retira de son long séjour de plusieurs années dans la péninsule, il déposa, selon Tite-Live, un énorme butin au trésor public. ${ }^{43} \mathrm{Il}$ en fut de même pour ses successeurs aux postes de l'Hispania Citerior et de l'Hispania Ulterior: en 198, L. Manlius Acidinus ne reçut pas l'ovation demandée, mais déposa néanmoins un riche butin au trésor public; ${ }^{44}$ en 196, Cn. Cornelius Lentullus reçut les honneurs de l'ovation et déposa un riche butin au trésor public; ${ }^{45}$ la même année, $L$. Stertinius, qui revenait d'Hispania Ulterior, ne demanda pas le triomphe ni les honneurs de l'ovation, mais se "contenta", selon Tite-Live, de rapporter un riche butin et de faire construire deux arcs de triomphe dans le forum Boarium, devant le temple de la Fortune et celui de la déesse Matuta Mater, et un troisième dans le grand cirque; il plaça des statues dorées sur ces arcs. ${ }^{46}$

Hormis l'épisode du soulèvement orchestré par Indibilis et son frère Mandonius, l'Hispania, dans son ensemble, est restée relativement calme durant les cinq années

38 Liv. 29.1.21-22; voir également App., Ib. 38.153.

39 Liv. 29.2.2.

40 Liv. 29.3.5.

41 García Moreno 1987, 211-243, et plus particulièrement 230-243; Harris 1989, 32 passim; Vallejo Girvés 1994, 170-171; Pina Polo 2006, 71-80; PAStor MuÑoz 2008, 41.

42 Liv. 31.20.1-7.

43 Liv. 31.20 .7$.

44 Liv. 32.7 .4

45 Liv. 33.27.1.

46 Liv. 33.27.3-4. 
qui s'écoulèrent entre 205 et 196, date du début de la guerre, et surtout 197 qui voit la création des provinces de l'Hispania Citerior et de l'Hispania Ulterior et la fin du flou administratif et juridique qui accompagnait jusqu'alors l'emprise progressive de Rome sur la péninsule Ibérique. Durant toute cette période, l'Hispania a néanmoins été soumise à des prélèvements de richesses conséquents qui expliquent les butins plus imposants les uns que les autres, que les proconsuls ou les consuls en charge de ce pays en rapportèrent. Jusqu'à cette date, les récits de Tite-Live ne nous donnent aucune indication sur la nature des rapports qu'entretinrent les Hispani avec les Romains. On peut supposer qu'ils ne furent pas tous amicaux et que bien des prélèvements durent être obtenus par la force des armes, comme le suggère fortement le fait que les généraux qui rentraient de l'Hispania réclamaient les honneurs du triomphe ou, à défaut, ceux de l'ovation. Il faut donc imaginer que Rome dut y mener une guerre de prédation larvée, juste bonne à asseoir définitivement son hégémonie sur les populations locales et à s'enrichir à leurs dépens. ${ }^{47}$ Les rares renseignements fournis par Tite-Live au sujet des évènements de la péninsule ne permettent pas de déduire quoi que ce soit sur les causes des conflits qui s'y déroulaient. L'auteur ne fait jamais allusion à des actes de brigandage qu'il eût fallu réprimer. Cette guerre qui ne présenta apparemment aucune action mémorable se déroula en vase clos avant que les rapports de force ne tournent à l'avantage des Hispani et ne réclament de fait une intervention plus musclée de Rome.

Le tournant se situe au printemps de l'an $197^{48}$ quand les Hispani prirent les armes. ${ }^{49}$ Comme pour l'action militaire menée en 205 par Indibilis, ce sont une nouvelle fois des rois, notamment Culchas et Luxinius $^{50}$ ou des généraux dont on ne connaît pas le rang (Boudar, Baesado), ${ }^{51}$ et non pas des brigands, qui prirent les armes contre Rome. À ce moment-là, ce sont les deux provinces d'Hispania Ulterior ${ }^{52}$ et d'Hispania Citerior $^{53}$ qui se soulèvent contre l'occupant. L'arrivée de Caton en Hispania Citerior en 195 marqua une nouvelle phase dans le déroulement des opérations militaires. ${ }^{54}$ La guerre menée par Caton prit immédiatement la tournure de représailles conduites contre un ennemi qui n'avait rien du brigand. Selon Tite-Live, il "mit à feu et à sang le territoire ennemi, et répandit partout l'épouvante et la consternation". ${ }^{55}$ Or, quand on a affaire à des brigands, on ne ravage pas le pays, on ne le met pas à feu et à sang. En revanche, on les pourchasse dans leurs repères et on les contraint à la reddition.

\footnotetext{
47 Schulten 1935, III, 174 et 228.

48 Liv. 33.26.5.

49 Liv. 33.26.6; l'assertion de Liv. est fausse. Il semble oublier que le soulèvement d'Indibilis et de Mandonius n'entretint aucun rapport avec Carthage.

50 Liv. 33.21.7-8. Sur Culchas (chez Tite-Live) ou Colichas (chez Polybe), qui avait levé 3000 fantassins et 500 cavaliers pour lutter aux côtés des Romains, en 206, voir Plb. 11.20.3; Liv. 28.13.2. Selon Liv. il dominait 28 oppida en 206. Au moment de sa révolte en 197, il n'est plus à la tête que de 17 oppida. Après bien d'autres historiens, ÉTIENNE 1958, 50, voit dans cette réduction de sa souveraineté l'origine de son mécontentement et de sa révolte.

51 Liv. 33.44.4.

52 Liv. 33.21.6-8.

53 Liv. 33.25.8-9.

54 Sur l'action de Caton en Hispania, voir, entre autres, KnAPP 1980, 21-56.

55 Liv. 34.9.13 (trad. Désiré Nisard, Paris, 1864).
} 
Le mode opératoire choisi par Caton pour briser la résistance des Hispani correspond clairement à une guerre conventionnelle, menée contre une population ennemie.

Dans le même temps, M. Helvius, après avoir quitté l'Hispania Ulterior, à la tête d'une armée forte de 6000 hommes, livrait une bataille victorieuse sous les murs d'Iliturgi contre 20000 Celtibères. ${ }^{56}$ La victoire et la prise de la ville ont été suivies du massacre de toute la jeunesse. Cet acte, comme les déprédations commises par Caton, témoignent de mesures coercitives caractéristiques d'un temps de guerre et non pas d'opérations de police menées contre des brigands. C'est du reste parce que ces opérations étaient des opérations de guerre et non pas de police que la prise du butin était possible. Aussi, comme ses prédécesseurs, Helvius, après ce coup d'éclat, rentra à Rome pour y recevoir les honneurs de l'ovation -le triomphe lui fut refusé- et déposer dans le trésor public un butin particulièrement important, fruit de ses exactions et de ses massacres. ${ }^{57}$ Son successeur, $Q$. Minucius, connut en revanche les honneurs du triomphe à son retour d'Hispania Ulterior. Le butin qu'il déposa au trésor public s'élevait à une somme bien supérieure, comparée à celle du butin d'Helvius. ${ }^{58}$

La suite du récit de Tite-Live montre bien que les forces indigènes contre lesquelles les généraux romains luttaient étaient composées de milices civiques. Les propos que Tite-Live prête au roi des Ilergètes, Bilistage, ne laissent pas place au doute, ce sont bien des milices civiques ennemies qui assiègent la ville, à la fin de l'hiver de l'an 195. ${ }^{59}$ La réponse de Caton ${ }^{60}$ mais aussi et surtout la teneur du discours qu'il adresse à ses officiers assemblés pour leur expliquer la situation politique de l'Hispania et l'enjeu de la bataille qu'il s'apprête à livrer à l'armée ennemie ne font que confirmer l'hypothèse défendue ici:

Voici, leur dit-il, l'occasion que vous avez souvent désirée de faire éclater votre courage. Jusqu'à présent vous avez plutôt fait une guerre de partisans que livré des combats réguliers: vous allez maintenant en venir aux mains avec les ennemis en bataille rangée. Il ne s'agit plus de ravager des campagnes; vous pourrez piller les trésors des villes. [...] Il faut que vos armes et votre valeur en fassent de nouveau la conquête [des possessions en deçà de l'Ėbre]; il faut que ces nations, qui montrent toujours plus d'empressement pour la révolte que de fermeté dans la résistance, soient forcées de rentrer sous le joug qu'elles ont secoué. ${ }^{61}$

Nonobstant l'emphase de la rhétorique habituelle de Tite-Live, ce discours remet définitivement en cause l'idée qui voulait voir dans le manque de terres et la pauvreté

56 Liv. 34.10.1-2.

57 Liv. $34.10,3-5$.

58 Liv. 34.10.6-7.

59 Liv. 34.11.2-3; il est intéressant de constater que Liv. (28.32.8-9) qualifiait en 206 les Ilergètes de brigands et leurs chefs de chefs de brigands. Depuis qu'ils ont été soumis par Rome et qu'ils sont devenus ses alliés, il n'est plus question de brigands. Sur les armées hispaniques voir en particulier Quesada SANZ 2006, 149-167; ID. 2006a, 245-263. Sur les guerres de conquêtes de l'Hispani, voir les travaux récents publiés sous la direction de CAdiou et alii (éd.) 2008; Quesada Sanz et alii (coords.) 2010; Cadiou - Navarro Caballero (éd.) 2014.

60 Liv. 34.11.3-4.

61 Liv. $34.13 .5-6$ et 9. 
les causes des guerres qui opposèrent les Hispani aux Romains. D'ailleurs, le fait que les Turdétans aient enrôlé des mercenaires à leur service pour lutter contre Rome enlève toute ambiguïté possible. ${ }^{62} \mathrm{La}$ lutte avait pour objectif le contrôle des régions occupées par Rome et les richesses qu'elles produisaient. La victoire de Caton en témoigne. À peine avait-il défait l'armée ennemie, qu'il ordonnait à ses hommes, après quelques heures de repos seulement, de piller la campagne. ${ }^{63}$ Toutefois, face à l'impossibilité des Romains d'exercer un contrôle absolu de l'ensemble du territoire conquis, la moindre défaillance, la moindre rumeur d'un départ éventuel ou d'une difficulté, même passagère, avait pour effet d'inciter les Hispani à tenter de nouveau leur chance afin de recouvrer leur indépendance. ${ }^{64}$

La réaction romaine ne tardait jamais à se faire sentir. Elle était d'autant plus impitoyable que les indigènes avaient épuisé leur recours en grâce auprès d'un conquérant pour qui seuls comptaient les bénéfices économiques et honorifiques qu'il savait pouvoir retirer de l'entreprise. Toute considération humanitaire étant d'emblée écartée au nom de la supériorité de la civilisation sur la barbarie, il ne restait plus aux indigènes comme échappatoires que vaincre ou mourir. Pour ceux qui en réchappaient, l'alternative se situait, selon le bon vouloir du conquérant, entre l'esclavage ${ }^{65}$ ou une liberté sous contrôle qui se signalait notamment par la perte de toute autonomie politique. Pour y parvenir, c'est-à-dire pour prévenir toute possibilité de soulèvement futur, Rome recourait à la menace et à la puissance de ses armes. Elle chercha surtout à briser toute velléité de soulèvement en enlevant aux Hispani la possibilité de se prémunir des attaques romaines en se réfugiant dans des sites fortifiés. ${ }^{66}$

Selon Tite-Live, Caton aurait clairement exprimé, devant les sénateurs des peuples indigènes, l'objectif à atteindre: il était de leur intérêt de rester soumis et pour ce faire il allait les réduire à l'impuissance ${ }^{67}$ Les dernières opérations militaires de la campagne de Caton se résumèrent en effet à une suite de sièges menés victorieusement contre les places fortes des Sédétans, des Ausétans, des Suessétans, des Lacétans et des Vergistans. ${ }^{68}$

La conclusion de ces premières années de guerre nous est donnée par Tite-Live sous la forme d'une sorte de résumé sentencieux de la situation au moment de l'arrivée de Caton en Hispania et de son action militaire:

Le consul éprouvait beaucoup plus de difficultés à soumettre l'Espagne que les premiers généraux envoyés dans ce pays. Ceux-ci avaient vu les Espagnols, fatigués de

62 Pour les références aux mercenaires celtibères embauchés par les Turdules / Turdétans, voir Liv. $34.17 .4 ; 19.1-10$.

63 Liv. 34.16.4-7.

64 Liv. 34.16.8-10.

65 Par exemple Liv. 34.21.6, qui dit qu'une partie des Vergistans fut vendue en esclavage.

66 Liv. 34.17.11. Selon Schulten 1935, III, 185, il s'agirait des cités de l'Èbre, et non pas celle du Bétis, comme le dit Plu., Cat. Mai., 10.3.

67 Liv. 34.17.7-8.

68 Liv. 34.20.1-9. 
la domination carthaginoise, se donner à eux. Caton les trouvait en possession de leur liberté, et il lui fallait les remettre pour ainsi dire en esclavage. ${ }^{69}$

Tout au long de ces années de guerre, il n'a été fait mention qu'une seule fois de brigands, à l'occasion de la dernière action militaire de Caton contre Vergium Castrum. ${ }^{70}$ Selon Tite-Live, des brigands auraient élu domicile dans cette ville, apparemment contre la volonté de ses habitants, afin de s'en servir comme d'un refuge leur permettant de piller impunément les terres voisines. Cette mention semble cependant quelque peu décalée par rapport au reste du récit livien et ce pour deux raisons essentielles: d'une part, elle ne concerne pas directement, contrairement aux autres épisodes narrés précédemment, la lutte contre Rome ou contre les populations alliées de Rome. Jusqu'à présent, Tite-Live avait présenté des faits de guerre où l'on voyait des armées s'affronter en bataille rangée ou assiéger les places fortes de l'ennemi. Ici, il est exceptionnellement question de brigands qui pillent les terres voisines de Vergium Castrum, mais n'attaquent pas les légions romaines; d'autre part, l'action menée par Caton s'apparente plus, contrairement ici aussi aux autres épisodes précédents, à du maintien de l'ordre. Plutôt qu'une opération militaire, c'est avant tout une opération de police. La manière dont Caton règle le problème que pose la présence de ces bandits dans Vergium Castrum est d'ailleurs représentative du mode opératoire classique en pareil cas. Alors que les guerriers qui combattent dans les rangs des milices civiques sont faits prisonniers, c'est du moins ce qu'il est possible de déduire des silences de Tite-Live sur le devenir des combattants vaincus au cours de la guerre contre Rome, les brigands, comme toujours, subissent la rigueur des châtiments exemplaires et expéditifs. La mort étant le lot commun des individus accusés de brigandage, ceux de Vergium Castrum ne font pas exception à la règle. Ils sont tous condamnés à mort (praedonibus supplicium sumpsit). Les habitants de Vergium Castrum sont séparés en deux groupes: ceux du premier sont libérés, ainsi que leurs parents, car ils ont aidé Caton à prendre la ville des mains des brigands; ceux du second groupe sont, en revanche, réduits en esclavage. Le sort réservé à chaque groupe est en parfaite conformité avec les usages de la guerre de cette époque. S'il est fréquent que les habitants d'une ville assiégée se fassent massacrer jusqu'au dernier, il arrive aussi, bien plus fréquemment qu'on ne le croit, qu'ils soient réduits en esclavage, à l'exception d'une petite minorité d'entre eux qui en réchappent pour des raisons variées, notamment pour l'aide qu'ils ont apportée aux assiégeants. Le déroulement de l'épisode, mais aussi et surtout sa conclusion, présente donc une sorte de mélange entre faits de brigandage et faits de guerre qui tranche nettement avec le récit des guerres livrées en Hispania par Rome.

Mais reprenons le déroulement chronologique du récit livien au point où nous l'avons laissé, c'est-à-dire au moment du départ de Caton pour Rome. Nous sommes en 194, Caton parti, l'Hispania connaît de nouvelles tentatives de soulèvement des populations indigènes. C'est semble-t-il avec difficulté et sans grand succès que son successeur à la tête des armées romaines de l'Hispania Citerior, le préteur Sex. Di-

69 Liv. 34.18.1-2.

70 Liv. 34.21.1-6. 
gitius, réussit à maintenir tant bien que mal la situation sous contrôle, tandis que le préteur d'Hispania Ulterior, P. Cornelius Scipion Nasica, parvenait à vaincre les Lusitaniens en les attaquant non loin d'Ilipa, au cours de leur marche, au moment où ils retournaient chez eux chargés d'un important butin. ${ }^{71}$ L'année suivante, c'est une armée confédérée de Vaccéens, de Vettons et de Celtibères qui dévaste l'Hispania Citerior. Ils sont finalement battus par M. Flavius Nobilior aux environs de Tolède. Tite-Live précise qu'au cours de la même année, C. Flaminius, après s'être emparé d'une place nommée Inlucia chez les Orétans, livra plusieurs combats obscurs pour mettre fin "à des courses de brigands plutôt que d'ennemis" (aduersus latronum magis quam hostium excursiones). ${ }^{72}$ La guerre se poursuivra en 192 dans l'Hispania Ulterior, sous le commandement de C. Flaminius, et en Hispania Citerior, sous celui de M. Fulvius. Ce dernier vaincra une armée de Vettons venue prêter main-forte aux habitants de Tolède assiégés. ${ }^{73}$ Jusqu'ici, hormis l'allusion à la lutte qui a opposé Flaminius à des troupes qui se comportaient comme des brigands, les ennemis de Rome apparaissent comme autant d'entités politiques autonomes. Pour le moment, il n'est nullement question de brigands, même si les allusions répétées au pillage des campagnes laissent à penser que la lutte qui s'engage contre Rome n'a pas pour seul objectif des visées politiques. Du côté romain, en revanche, cette succession de combats, parfois obscurs, de sièges et de prises de villes, annonce la tactique des colonnes mobiles des armées européennes lancées à la conquête de l'Afrique. Aucun fait marquant, si ce n'est de temps en temps la prise d'une ville plus importante que les autres, ne vient attirer l'attention sur ce qui se passe dans la péninsule. Il est vrai que la lutte est plutôt indécise, comme l'indique Tite-Live lui-même. ${ }^{74}$

Derrière les non-dits de l'historien padouan et ses nombreuses allusions, on perçoit néanmoins le quotidien de cette guerre de conquête qui se décline en exactions et autres massacres perpétrés par les légions dans le but de soumettre les indigènes et de briser toute velléité de résistance. ${ }^{75} \mathrm{C}$ 'est assurément pour lutter contre la terreur, le mot est de Tite-Live, ${ }^{76}$ que Rome fait régner contre ceux qui refusent de se soumettre, que les peuples de l'Hispania s'arment et attaquent inlassablement les possessions romaines. Les Hispani y gagneront leurs titres de gloire.

Parmi les différents auteurs classiques qui nous ont laissé un témoignage des guerres de l'Hispania, Tite-Live est assurément, après Polybe, celui qui ne tenta pas d'appliquer sur les réalités de la lutte des schémas explicatifs anachroniques ou étrangers au contexte local. Pour l'historien padouan, du côté des Hispani, comme

71 Liv. 35.1.5-12.

72 Liv. 35.7.7.

73 Liv. 35.22.5-8.

74 Liv. 35.1.1-2.

75 Contra Sánchez Moreno 2011, 97-103, qui propose de "emplazar a las comunidades peninsulares de los siglos III y II a.C. en un escenario de negociación que en uno de resistencia. Al sentido reduccionista y anacrónico de este último término contrapone el de nagociación un espacio más diáfano y adaptativo que, al lado de la gestión diplomática, no evade la articulación militar y otras políticas abiertamente hostiles a las aspiraciones imperialistas de la Urbs en Hispania". On pourrait répondre que la résistance n'implique pas le refus de négociation et que la négociation peut être perçue comme une forme passive de résistance; un moyen de s'opposer et de défendre ses acquis et ses intérêts sans recourir aux armes.

76 Liv. 35.1.3 (trad. Richard Adam, Paris, 2004). 
des Romains, les causes de la guerre restent clairement identifiables: les premiers luttent pour recouvrer ou préserver leur indépendance, les seconds pour imposer leur hégémonie. À aucun moment l'auteur ne fait référence ou allusion à la pauvreté du pays ou des gens, encore moins à des inégalités sociales, pour justifier l'acharnement des indigènes à rallumer la guerre. Il ne fait pas non plus référence, sauf exception -encore s'empresse-t-il de reconnaître, pour un des deux seuls cas cités, qu'il n'est pas en mesure de juger du statut réel des protagonistes (brigands ou ennemis)-, aux brigands. Comparé à ceux de Diodore et d'Appien, le récit de Tite-Live parait bien neutre et somme toute plus objectif même s'il nous induit en erreur en limitant l'explication de l'antagonisme entre Hispani et Romains au désir des premiers de résister à la domination des seconds.

\section{L'affaire de Compléga ou l'émergence du problème du manque de terres dans l'Ibérique d'Appien}

Du soulèvement organisé sous le commandement d'Indibilis, en 206, jusqu'à l'an 180-179, date de l'intervention de Tib. Sempronius Gracchus en Espagne, le récit d'Appien se limite à présenter les hauts faits et gestes de Caton en un raccourci saisissant, entre l'action qu'il mena au moment de son débarquement à Emporion (195) et le stratagème auquel il a eu recours pour obliger les villes de la vallée de l'Èbre à démanteler leurs fortifications, en l'espace d'une seule journée. ${ }^{77}$ À aucun moment, l'auteur ne fait référence à des actes de brigandage. Ce n'est qu'à partir de 182-181, ${ }^{78}$ sous la préture de Fulvius Flaccus, qu'Appien met en avant, pour la première fois, le problème du manque de terres pour expliquer la révolte de certains peuples de l'Hispania. Pour l'historien d'Alexandrie, c'est en 180, soit une quinzaine d'années après le départ de Caton, que "beaucoup d'Ibères, manquant de terres, se révoltèrent contre Rome. Ce fut en particulier le cas des Lusoniens, qui étaient installés dans les parages de l'Èbre". ${ }^{79}$

Ayant été vaincus par les troupes de Fulvius Flaccus dans une bataille rangée, les Ibères se dispersèrent en formant deux groupes d'inégale importance:

Un grand nombre de vaincus furent dispersés entre les cités. Mais ceux qui manquaient le plus de terres et vivaient de maraudage allèrent chercher refuge dans la ville de Compléga, une place-forte nouvellement fondée qui se développait rapidement. ${ }^{80}$

Le premier groupe comprend sans doute les milices civiques relevant de plusieurs tribus, dont Appien nomme l'une d'entre elles "la tribu des Lusoniens". ${ }^{81}$ C'est ce qui explique pourquoi elles se dispersèrent entre les villes après avoir été battues. On

77 App., Ib., 38.156 à 41.170.

78 La date de 179 avancée par Appien est erronée, voir GouKowsKy 2003, 37, n. 252.

79 App., Ib., 42.171.

80 App., Ib., 42.172.

81 Voir Strab. 3.4.13; selon Goukowsky 2003, 37, n. 253, ils contrôlaient, semble-t-il, la haute vallée du Tage et celle du Jalon. 
peut penser que les différents contingents durent chercher à regagner la ou les villes dont ils étaient originaires.

Le statut de ceux qui composaient le second groupe est plus difficile à saisir.

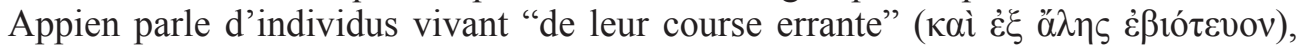
c'est-à-dire de maraudeurs ou vagabonds, mais pas encore de brigands. Du reste, la mention de brigands ne s'accorde pas avec le début du passage. En effet, la différence entre les deux termes est importante: le vagabond est un voleur occasionnel, plus exactement un individu sans domicile qui erre à la recherche d'une opportunité pour vivre aux dépens des autres. C'est celui qui rôde à travers la campagne. Contrairement au brigand, il n'est pas armé et ne commet pas de crime de sang. Pour autant, ils ont généralement été confondus avec des brigands en raison du rapprochement souvent tenté entre la Compléga d'Appien et la Kermeletes de Diodore. ${ }^{82}$ A. Schulten ${ }^{83}$ avait proposé de confondre les deux sites de Compléga et de Contrebia, ${ }^{84}$ à celui de Kermeletes, considérant, apparemment à tort, que le texte d'Appien était fautif. L'idée a été longuement débattue, sans toutefois qu'un consensus se fasse jour. Pour L. A. García Moreno, ${ }^{85}$ Compléga et Contrebia ne forment en réalité qu'une seule et même ville ${ }^{86}$ tandis que Kermeletes relèverait d'un autre épisode de la lutte entre les Romains et les indigènes. À moins d'envisager, comme le fait du reste García Moreno, d'identifier la cité des bandits des textes de Diodore et d'Appien, avec la Contrebia de Tite-Live: "tendríamos un testimonio de una de las formas de realización de dicho proceso sinoicístico" mettant en avant la possibilité de voir dans ces bandes de déshérités d'authentiques Heerhaufen migrantes. ${ }^{87}$

C'est dans le contexte de la guerre menée contre les Ibères et les Celtibères, que prend place l'affaire de Compléga, qui se termine par l'intervention de Tib. Sempronius Gracchus et une première distribution de terres. Aux yeux d'Appien, l'action raisonnée de ce dernier permet à Rome de contrôler de nouveau la situation, non par le recours aux armes qui ne peut aboutir à terme qu'à une détérioration progressive de la situation, préjudiciable aux divers protagonistes, mais par une politique censée répondre aux besoins des populations indigènes.

Dans l'optique défendue par Appien, la révolte des indigènes a été causée par le manque de terres. Mais ce manque ne se manifeste pas de manière homogène sur l'ensemble de ces sociétés. Parmi les indigènes, certains sont plus démunis que d'autres. Ce sont ceux qui possèdent des terres, mais visiblement en quantité insuffisante pour leur permettre de vivre décemment. Ce sont ces individus qui se sont regroupés à Compléga. Il ne dit toutefois pas que la ville a été fondée par eux. Il dit simplement qu'ils s'y regroupèrent, notamment après la défaite subie face aux troupes de Fulvius Flaccus, et que leur afflux généra une forte croissance urbaine. Aussi, plutôt que d'y voir des brigands, il serait sans doute plus juste d'y voir des déshérités, c'est-à-dire

82 D.S. $29.28 ; 33.26$

83 SChulten 1914, 136; ID. 1935, III, 213 et 214.

84 Liv. 40.33.1-2.

85 García Moreno 1993, 332.

86 Contra Tovar Llorente 1989, 340.

87 García Moreno 1993, 352; Richardson 2000, 140, ne se prononce pas. 
des petits propriétaires qui cherchaient, en se regroupant, peut-être à partir d'un processus de synocisme, comme l'a proposé L. A. García Moreno, à fonder une nouvelle structure politique susceptible de les aider à trouver les moyens d'une vie meilleure. Compléga apparaît dès lors comme une réponse à la conquête romaine et comme un refuge pour les habitants des oppida et autres établissements détruits. ${ }^{88}$ Dans ces conditions, il me paraît difficile d'accepter l'hypothèse de M. V. García Quintela, selon laquelle "le fait que les bénéficiaires soient désignés comme "pauvres" est seulement un effet de rhétorique". ${ }^{89}$

Ces gens démunis, sans doute à cause des ravages de la guerre et des exactions des gouverneurs qui se sont succédé à la tête de l'Hispania Citerior depuis le départ des Carthaginois, n'ont pas encore basculé dans le brigandage, autrement ils auraient été "irrécupérables" au regard de l'idéologie antique, laquelle rejetait le brigand dans une zone de non-droit rendant ainsi impossible toute solution négociée, mais favorable, en revanche, à toutes sortes d'exactions. On peut penser que l'idée d'Appien était de dénoncer une situation qui favorisait une certaine paupérisation des sociétés indigènes à qui Rome n'avait pas accordé toute l'attention nécessaire. En les présentant un peu comme les laissés-pour-compte des premiers temps de l'occupation romaine de la péninsule, Appien pointe du doigt les désordres qu'une telle attitude pouvait très rapidement engendrer. Nous sommes là dans une période où tout était encore possible. Pour Appien, il ne fait aucun doute que la prise en main des populations indigènes était encore envisageable, voire souhaitable, comme vont le montrer les évènements à venir. Mais pour cela il aurait fallu pouvoir compter sur des hommes justes. Or, Rome a bien souvent mis à la tête de ses provinces des hommes corrompus, avides de richesses et de gloire, prêts à tout pour accéder au triomphe. Le parjure et le déshonneur qui l'accompagnent n'ont pas gêné certains, qui n'hésitèrent pas à recourir à tous les moyens, même les plus abominables, comme le massacre des Lusitaniens, pour réussir. Dans tous les cas, Appien semble privilégier le dialogue et la recherche d'un compromis à l'emploi des armes.

C'est ce que montre très clairement la suite de son récit de l'affaire de Compléga. Quand ces mêmes individus, après avoir réclamé une sorte de compensation pour leurs hommes tombés au combat, prévinrent Fulvius Flaccus qu'il aurait à se repentir s'il ne quittait pas la péninsule de son propre chef, ce dernier, adepte de la manière forte, fit suivre les ambassadeurs et vint assiéger Compléga. Devant ce déploiement de force, les "maraudeurs" qui s'y étaient réfugiés prirent la fuite, mais continuèrent leurs pillages de la campagne voisine. ${ }^{90} \mathrm{Ce}$ n'est que l'année suivante que ces mêmes individus, ou d'autres, la relation d'Appien n'est pas très claire, soit 20000 hommes de Compléga, portant des rameaux de suppliants tentèrent, par ce stratagème, après s'être présentés devant Tib. Sempronius Gracchus -le successeur de Flaccus-, de

88 Pena 1994, 253, dit, à tort, que "l'existence de cette ville était donc une conséquence de la mobilité et du vagabondage des populations indigènes dus à leur fuite devant les armées du conquérant"; toujours à propos de l'interdiction qui avait été faite aux indigènes de fonder des villes sans l'autorisation de Rome, l'auteur ne prend aucune distance vis-à-vis du contenu idéologique du discours antique et se contente de le reproduire.

89 García Quintela 1991, 89.

90 App., Ib., 42.173-174. 
s'emparer du camp romain et de le piller. ${ }^{91}$ Utilisant à son tour une feinte, il réussit à reprendre le contrôle de la situation, à massacrer un grand nombre des ennemis et à s'emparer de Compléga et de ses alentours. Mais contrairement à ses successeurs, Tib. Sempronius Gracchus fit le choix du dialogue et de la concession. C'est du moins la conclusion à laquelle nous convie la lecture du dernier passage d'Appien concernant cette affaire, que l'historien présente comme le dénouement heureux d'une révolte commencée sous la préture de Fulvius Flaccus:

D'autre part, il [Tib. Sempronius Gracchus] installa les Ibères démunis de ressources en leur distribuant des lots de terres, et il conclut avec tous les habitants de cette région des conventions minutieuses, réglant les conditions dans lesquelles ils seraient amis des Romains. On échangea des serments dont, au cours des guerres ultérieures, on regretta souvent la rupture. ${ }^{92}$

On remarquera qu'Appien ne dit pas non plus que Tib. Sempronius Gracchus installa tous les Ibères habitant dans Compléga et sa région en leur distribuant des lots de terres. L'auteur précise que seuls les plus démunis d'entre eux ont ainsi été lotis. La mesure "sociale" de Tib. Sempronius Gracchus ne concerne qu'une partie des indigènes. Plus exactement ceux qui, lors de l'épisode précédent, avaient fui de leur côté et s'étaient réfugiés à Compléga. On perçoit ainsi, derrière le discours "social" d'Appien, des préoccupations plus politiques. Cette politique d'octroi de terres par les autorités républicaines était uniquement destinée à fixer les populations incriminées dans ce long conflit, pour mieux les contrôler. Pour sa tranquillité, Rome doit veiller à aider les pauvres à se lotir, seule manière pour endiguer la menace que ces gens font peser sur les territoires déjà "soumis" ou en passe de l'être. Ces gens ne sont pas des brigands, mais des déshérités à la recherche de moyens de subsistance, quitte à piller les biens de leurs voisins. Bien qu'ils agissent avec perfidie, puisqu'ils tentent de déjouer la vigilance des Romains en se présentant comme des suppliants venus faire leur soumission, ils n'en constituent pas moins un groupe auquel Appien se refuse d'appliquer le qualificatif de brigand. La distribution de terres à laquelle procéda Tib. Sempronius Gracchus prend ici valeur exemplaire. Car non seulement cette mesure "révolutionnaire" aura permis à Rome de lier, pour un temps au moins, les indigènes de la région à son destin, mais elle lui aura aussi permis de lutter efficacement, et avec de bien meilleurs résultats que le recours à la force militaire, contre les risques de voir une partie importante des populations indigènes basculer dans le brigandage. Car c'est assurément là que se situe en partie la cause véritable du fameux brigandage des Lusitaniens et non pas dans un hypothétique manque de terres.

\footnotetext{
91 App., Ib., 43.178.

92 App., Ib., 43.179. Les alliances durent apparemment concerner les Belloi, les Lusoniens, les Titthoi et peut-être les Arévaques. Sur la teneur de ces alliances et les réactions indigènes aux conditions imposées par Tib. Sempronius Gracchus, voir Goukowsky 2003, 39, n. 268.
} 


\section{Les guerres lusitaniennes d'après l'Ibérique d'Appien (155-139) ou l'omnipré- sence du brigand}

Entre la fin du mandat de Tib. Sempronius Gracchus et le début des guerres lusitaniennes (155-139), Appien ne fera jamais mention de brigands. Tout au long du récit des guerres contre les Celtibères (154-133), l'attention de l'historien se portera sur le problème évoqué de manière implicite dans l'affaire de Compléga, à savoir celui du contrôle des populations indigènes à travers la mise en place d'une politique de fixation de l'habitat. ${ }^{93}$ Tout au long des évènements liés à l'intervention de $\mathrm{L}$. Lucinius Lucullus, le consul en charge de la "pacification" (151), Appien présentera toujours les indigènes comme des entités politiques autonomes. C'est en tant que telles qu'elles combattirent l'occupant romain et tout particulièrement l'avidité de Lucullus qu'Appien présente comme un fou criminel poussé par la soif de l'or et de l'argent". ${ }^{94}$ La guerre que mena Lucullus est en effet, aux dires d'Appien, une guerre injuste dont la raison d'être est à rechercher dans la cupidité de l'auteur avide de gloire. ${ }^{95}$

Durant toute cette longue période de guerre ininterrompue, à l'exception de l'épisode lusitanien, que nous allons examiner maintenant, Appien a évité de parler de brigandage pour qualifier les opérations guerrières menées par les populations indigènes. Même les attaques perpétrées contre les troupes de Fulvius Flaccus et les alliées de Rome n'ont pas été le fait de brigands, si l'on en croit l'historien d'Alexandrie. Pourquoi, à partir du moment où la guerre ne concerne plus les théâtres d'opérations de l'Hispania Citerior, mais ceux de l'Hispania Ulterior, Appien parle-t-il de brigandage?

Appien fait débuter son récit des guerres lusitaniennes en 155, or on sait, notamment par Tite-Live, que dès 194, les Romains étaient en lutte contre eux. Selon Appien, le manque de terres et la recherche du butin auraient été les deux éléments déclencheurs des hostilités. Pour autant, quand les Lusitaniens entament les hostilités en 153, sous le commandement de Punicus, ils se contentent de piller les territoires occupés par les populations alliées de Rome. En 152, les Lusitaniens et les Vettons, qui s'étaient déjà joints à eux l'année précédente, furent attaqués par M. Atilius, avec qui ils firent la paix. ${ }^{96}$ Mais à peine ce dernier rentré à Rome, ils reprirent les armes et attaquèrent des sujets de Rome. Ils furent dès lors confrontés à Servius Galba (150), le successeur d'Atilius, qu'ils vainquirent. ${ }^{97}$ L'année suivante, Lucullus, qui faisait la guerre sans autorisation aux Vaccéens en Hispania Citerior ${ }^{98}$ et Galba attaquèrent chacun de leur côté les Lusitaniens, notamment une armée qui traversait le détroit

93 L'affaire de Ségéda, qui est à l'origine du déclenchement des guerres de Celtibérie menées dans un premier temps contre les Belloi, puis contre d'autres peuples venus les soutenir, n'est que le prolongement de celle de Compléga, plus exactement du traité conclu entre Tib. Sempronius Gracchus et ces mêmes peuples, voir App., Ib., 44.180-183.

94 App., Ib., 51.215.

95 App., Ib., 53.223; 55.233.

96 App., Ib., 58.243.

97 App., Ib., 58.244-246.

98 App., Ib., 51.215; 59.247. 
près de Gadès. ${ }^{99}$ Ils leur infligèrent de lourdes pertes, puis s'attaquèrent à la Lusitanie qu'ils ravagèrent. Face aux attaques romaines, les Lusitaniens se résignèrent à envoyer des ambassadeurs à Galba afin d'appliquer le traité conclu deux années auparavant avec Atilius. C'est ici que se situe l'épisode du massacre des Lusitaniens qui s'étaient rassemblés à la demande de Galba, afin que ce dernier procédât à une distribution de terres censées les fixer et endiguer définitivement leurs courses vagabondes et leurs rapines. ${ }^{100}$ Selon Galba, dont Appien est supposé nous avoir rapporté les paroles, c'est la misère due à la pauvreté du sol de la Lusitanie qui les aurait poussés à attaquer leurs voisins:

....s'ils se livraient au brigandage, faisaient la guerre et violaient les traités, leur dénuement en était la cause. "C'est en effet», dit-il, «la pauvreté de votre sol et votre indigence qui vous amènent au brigandage. Mais moi, à des amis dans le dénuement, je ferai don d'un territoire fertile, et je vous installerai au sein de l'abondance, après vous avoir divisés en trois groupes." ${ }^{101}$

Le topos de la pauvreté comme vecteur du brigandage est pour la première fois ici clairement énoncé. Pour les tenants de la communis opinio, le fait que Galba ait accepté, en apparence tout du moins, les conditions des Lusitaniens suggère fortement que les Romains étaient parfaitement conscients de la vraie raison de ces activités guerrières qui leur avaient aliéné une grande partie de la jeunesse lusitanienne au détriment des traités signés deux années plus tôt entre les peuples lusitaniens et Atilius. G. Chic García, par exemple, considère qu'aux yeux des autorités lusitaniennes les agissements guerriers de la jeunesse se justifiaient par le fait que c'était la pauvreté de la terre qui les poussait à ne pas respecter les termes des traités conclus précédemment et à piller des terres qui, selon les traités, étaient normalement inviolables. ${ }^{102}$ Je ne peux cependant que rejeter fermement les interprétations de G. Chic García, et tout particulièrement celle selon laquelle Galba, au vu des précédents connus, aurait pu profiter de cette occasion pour mettre un terme aux actions de pillage en établissant "los excedentes de población en nuevas tierras". ${ }^{103}$ Car, en disant cela, l'auteur, qui accepte explicitement l'idée que le manque de terres est la conséquence d'une surpopulation, tombe de nouveau dans les travers de l'interpretatio Romana ou Grae$c a$ qui y voyait avec la pauvreté des sols et/ou le manque de terres les causes principales des problèmes auxquelles étaient confrontées les sociétés barbares.

En effet, si tout au long de cette période, les Lusitaniens entreprirent de ravager systématiquement les terres des régions voisines (Turdétanie, Carpétans, Bastitanie)

\footnotetext{
99 App., Ib., 59.247-248.

100 App., Ib., 59.249. Pour une approche critique de l'événement du point de vue de l'historiographie antique, voir GARCÍA Quintela 1991, 78-85.

101 App., Ib., 59.250.

102 Chic García 1980, 24; dans le même sens, Vallejo Girvés 1994, 173, considère que les bandits étaient en phase avec leur société d'origine et qu'ils n'y étaient pas perçus de manière péjorative.

103 App., Ib., 69; sans fondement, CHIC GARCÍA 1980, 24, considère que la terre qui sera distribuée le sera pour y établir un excédent de population lusitanienne, plus particulièrement les jeunes.
} 
ou d'exiger des rançons des propriétaires afin de ne pas détruire leurs récoltes, ${ }^{104} \mathrm{le}$ manque de terres n'est évoqué qu'à deux occasions et pas du tout de manière systématique pour expliquer leur soi-disant brigandage. Par exemple, ce n'est pas ce qui ressort précisément du texte d'Appien, quand il relate les déboires d'une bande d'une dizaine de milliers d'hommes, rescapés des massacres de Galba, qui s'est trouvée acculée à se rendre au préteur Gaius Vetilius:

Peu après, ceux qui avaient échappé à la scélératesse de Lucullus et de Galba formèrent une bande d'environ dix mille hommes, et ils se livraient à des incursions en Turdétanie. Gaius Vetilius arrivé de Rome avec quelques nouvelles troupes, y avait adjoint les effectifs stationnés en Ibérie. Disposant au total d'environ dix mille hommes, il tomba sur les Lusitaniens occupés à piller, leur infligea de lourdes pertes et rabattit les survivants vers un bourg fortifié où il leur fallait s'exposer soit à la famine, s'ils restaient sur place, soit aux coups des Romains, s'ils quittaient les lieux, tant le terrain était difficile. C'est pourquoi ils envoyèrent à Vetilius des émissaires munis de rameaux de suppliants: ils demandaient un territoire où s'établir à demeure, car ils avaient l'intention d'être à compter de ce jour entièrement soumis aux Romains. ${ }^{105}$

Il convient de comprendre que ces gens qui s'apprêtent à capituler ou à faire leur deditio, selon que l'on considère qu'il y a eu ou non recours à la force pour les amener à se rendre, ${ }^{106}$ sont a priori au courant des usages romains en matière de reddition. Ils savent que depuis maintenant plus d'un demi-siècle, les autorités romaines qui occupent la péninsule procèdent le plus souvent à de nouvelles assignations de terres aux populations soumises afin de mieux les contrôler. Il n'y a donc rien dans ce passage qui puisse laisser entendre que les Lusitaniens réclamèrent des terres où s'établir car ils n'en possédaient pas suffisamment pour subvenir à leurs besoins. Le fait de pratiquer le pillage des territoires voisins du sien n'est pas non plus la preuve que la société lusitanienne ait souffert de troubles sociaux internes ou d'une forte paupérisation d'une partie de sa population. Le pillage, de tout temps, représente la manière la plus simple et la plus rapide d'acquérir gloire et richesses. Il ne s'agit aucunement d'une activité réservée aux pauvres ou aux sociétés confrontées à des troubles sociopolitiques internes graves. Quand Appien dit que les Lusitaniens réclamèrent un territoire où s'établir à demeure, il faut donc comprendre qu'ils acceptaient de s'établir là où les Romains le souhaiteraient, conformément aux lois de la guerre qui livrent le vaincu à la discrétion du vainqueur. Par ailleurs, pour qu'il y ait deditio, il faut que la lutte oppose l'Urbs à un peuple, c'est-à-dire deux entités politiques autonomes, et non pas une cité et une bande de brigands. ${ }^{107} \mathrm{Il}$ paraît donc peu probable que Gaius Vetilius ait accepté de négocier et de conclure un accord avec des brigands, et encore moins qu'il ait promis de répondre favorablement à leur demande. On doit conclure que les Lusitaniens ont été identifiés comme formant un peuple en armes et non pas comme une bande de brigands, c'est ce qui leur a permis d'envoyer des émissaires

104 App., Ib., 61.256; 64.269 et 272; 66.281.

105 App., Ib., 61.256-258.

106 Sur la deditio, voir Auliard 2005, 255-270; ID. 2006, 139-156; García Riaza 2002; ID. 2011.

107 Voir à ce sujet le texte du bronze d'Alcántara, López Melero et alii 1984, 265-324. 
et de voir leur demande acceptée par Gaius Vetilius. Car, contrairement à la traduction proposée par P. Goukowsky (voir supra), Appien ne parle pas d'une bande de 10.000 hommes. Il dit simplement que les Lusitaniens se sont regroupés au nombre de 10.000

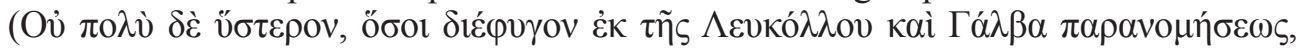

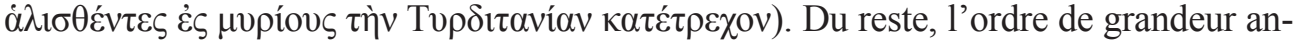
noncé par Appien renvoie tout naturellement à une véritable milice civique et non pas à un ramassis de brigands qui se seraient regroupés pour aller piller ensemble les territoires voisins du leur. ${ }^{108}$

Deux autres épisodes des guerres lusitaniennes tendent à confirmer l'hypothèse défendue ici. C'est tout d'abord celui de l'intervention de D. Iunius Brutus en Lusitanie, en l'an 138. Selon Appien, celui-ci aurait été envoyé en Lusitanie pour lutter contre les agissements de bandes de brigands qui parcouraient la région pour rivaliser avec les exploits de Viriathe. ${ }^{109}$ Confronté à des bandes particulièrement mobiles, Brutus renonça à les poursuivre. La raison évoquée est riche d'enseignements pour notre propos:

Envoyé contre celles-ci, Sextus Iunius Brutus renonça à les poursuivre à travers le vaste territoire que circonscrivent le Tage, le Léthès, le Dorios et le Baïnis, fleuves navigables, estimant que ce serait une entreprise difficile de surprendre des gens qui se déplaçaient rapidement, comme le font les bandes de brigands: il serait infamant pour lui de n'y point parvenir et, en cas de victoire, l'action n'aurait rien d'éclatant. ${ }^{110}$

En effet, il n'y avait dans l'Antiquité aucune gloire à vaincre des brigands. Aussi peut-on être assuré qu'ici, tout du moins en première approximation, les troupes dont nous parle Appien sont des brigands et non pas des milices civiques révoltées contre le pouvoir romain, puisqu'il affirme qu'il serait infamant pour Brutus de ne pas parvenir à les surprendre, et que de toute manière "l'action n'aurait rien d'éclatant". Au-delà du bien-fondé de l'identification qu'Appien fait de ces gens avec des brigands, ce passage a l'avantage d'aller dans le sens des conditions de la reddition des troupes lusitaniennes entre les mains de Vetilius. Si effectivement les troupes acculées à se rendre avaient été composées de brigands, il n'y aurait pas eu plus de gloire pour Vetilius à les vaincre qu'il n'y en aurait eu pour Brutus. On peut dès lors considérer que si le premier accepta de négocier avec les Lusitaniens, c'est tout simplement parce qu'ils n'étaient pas des brigands, mais des milices civiques se livrant au pillage du territoire ennemi. Est-il nécessaire de rappeler que dans l'idéologie antique, l'idée même d'une négociation avec des brigands n'était même pas concevable pour la simple et bonne raison qu'ils étaient assimilés à "des sauvages lâches et cruels, à des bêtes féroces". 111

Cependant, le fait qu'Appien précise que Brutus a fait le choix d'attaquer successivement les villes dont les brigands étaient originaires laisse à penser que contrairement à ce que nous venons de suggérer, il ne pouvait s'agir de vrais brigands mais bien de milices civiques, sachant que dans l'idéologie antique sont assimilés à des brigands

108 Dans le même sens, voIr Salinas de Frías 2008, 118.

109 App., Ib., 71.301.

110 App., Ib., 71.301.

111 CARrière 1981, 1-2; Flam-ZuCKERMANN 1970, 456 passim. 
tous les adversaires de l'ordre romain, qu'il s'agisse de pays entrés en rébellion, de populations dissidentes, de groupes marginaux, d'esclaves en fuite ou en révolte. ${ }^{112}$ D'ailleurs, Appien ne dit pas explicitement qu'il s'agissait de bandes de brigands, mais que ces troupes "se déplaçaient rapidement, comme le font les bandes de brigands" ( $\mu \varepsilon \theta \imath \sigma \tau \alpha \mu \varepsilon^{\prime}$ ov qu'il s'agisse pour autant de brigands.

Pour expliquer cet apparent paradoxe, il faut se résoudre à considérer que Brutus, plutôt que d'entamer une campagne militaire classique en tentant de rattraper un ennemi difficilement saisissable, a préféré, comme bon nombre de ses prédécesseurs, allier l'agréable à l'utile en pillant systématiquement les villes de la région. ${ }^{113}$

En assimilant les populations lusitaniennes à des populations dissidentes, Appien tentait ainsi de justifier aux yeux de ses lecteurs les exactions dont Brutus se rendit coupable en Lusitanie. Aussi, pour tenter d'expliquer la contradiction que l'on croit reconnaître entre le premier et le second passage du chapitre LXXI de l'Ibérique, il faut accepter l'idée qu'Appien a pu utiliser une source plutôt favorable à Brutus. C'est du reste l'interprétation avancée par P. Goukowsky ${ }^{114}$ pour expliquer le passage LXXIII, 308-310, où Appien montre une grande générosité à l'encontre des habitants de la ville de Talabriga qui auraient à plusieurs reprises manqué aux serments échangés avec lui. Selon Appien, il les aurait dépouillés de tous leurs biens (armes, chevaux, blé, argent du trésor public, ainsi que tous les autres biens collectifs), mais en leur laissant la vie sauve, après les avoir néanmoins terrorisés en leur laissant croire qu'il allait se livrer à des atrocités contre eux.

Pourquoi dès lors interrompre le récit des événements consacrés à Viriathe pour y insérer ces trois chapitres dédiés à Brutus? Le récit de l'intervention de Brutus n'apporte rien à la compréhension de la trame historique des guerres lusitaniennes. Parlant de la digression consacrée aux campagnes victorieuses de Brutus, P. Goukowsky considère, avec raison, que "c'est assurément là le plus grave défaut du livre, car ces chapitres rompent l'unité du récit consacré à Viriathe, et l'on voit mal l'utilité pratique de ce compromis boiteux entre la composition thématique et l'exposé chronologique des faits". ${ }^{115}$ La manière plutôt maladroite avec laquelle Appien tente d'expliquer, au début et à la fin de ces trois chapitres, ${ }^{116}$ les raisons qui l'ont poussé à rompre sa présentation thématique et à insérer ce court passage sur les agissements de Brutus en Lusitanie -au prétexte qu'ils ont commencé à la même époque du fait d'autres bandes désireuses d'imiter Viriathe- ne convainc pas, bien au contraire. Tout cela paraît clairement relever de la pirouette rhétorique destinée à justifier les déprédations commises par Brutus, à des fins d'enrichissement personnel. Appien lui-même, un peu plus loin, précise que Brutus a agi sur les injonctions de Lucullus, son beau-père, avec qui il avait partie liée, et que le mobile de ces actions injustes était purement crapuleux. ${ }^{117}$

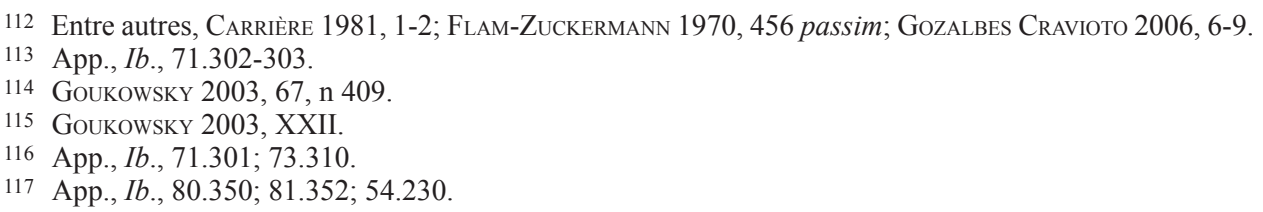


On peut dès lors considérer que ce n'est sans doute pas un hasard si dans deux des trois derniers chapitres qui précèdent le récit de l'intervention de Brutus, Appien mentionne, pour la première fois depuis le début des guerres lusitaniennes, deux combats mettant aux prises des brigands avec les légions romaines. La première action se déroule en 141, au moment où $Q$. Fabius Maximus Servilianus s'apprêtait à passer en Lusitanie pour y attaquer Viriathe. ${ }^{118} \mathrm{Il}$ est lui-même attaqué en cours de route par "une bande de brigands" forte de 10.000 hommes, mais dont il n'est pas dit si elle faisait ou non partie de l'armée de Viriathe. Elle aurait été commandée par deux chefs répondant aux noms de Curis et Apuleius. Après un premier succès au cours duquel Curis trouva la mort, la bande a été défaite et le butin dont elle s'était emparée a été repris.

L'année suivante, un chef de brigands, un certain Connobas, a été fait prisonnier par Maximus Emilianus, le frère de Servilianus. Connobas a été épargné, mais ses hommes eurent les mains coupées. ${ }^{119}$ De prime abord, il s'agit là d'un châtiment cruel en tout point conforme à ceux habituellement infligés à des brigands. Il semblerait cependant qu'Appien ait interprété ses sources au point de transformer des transfuges romains en brigands lusitaniens. C'est du moins ce qu'il est possible de conclure à la lecture des récits que Frontin ${ }^{120}$ et Valère Maxime ${ }^{121}$ nous ont laissés de cet événement. ${ }^{122}$ Frontin et Valère Maxime sont antérieurs à Appien, et parlent de transfuges romains châtiés et non pas de brigands. Aussi ne fait-il aucun doute qu'Appien a sciemment falsifié cet épisode pour qu'il serve pleinement à sa démonstration.

Mais ce n'est pas tout. Appien, n'étant pas à un paradoxe près dans son désir de présenter sous un jour plutôt favorable les opérations peu glorieuses de Brutus, va jusqu'à dire que la Lusitanie était parcourue par des bandes de brigands qui la pillaient. Or, toujours selon Appien, ce sont, jusqu'à présent, les Lusitaniens qui parcouraient les régions voisines de la Lusitanie pour les piller. Pourquoi dès lors se seraient-ils mis tout à coup à piller systématiquement leur propre pays? Il n'y a là aucune logique et ce d'autant plus si, comme l'affirme Appien, ces bandes agissaient ainsi pour rivaliser avec les exploits de Viriathe et l'imiter. Dans ces conditions, il aurait été plus cohérent qu'elles s'en prennent aux territoires des peuples voisins et non pas au leur.

On remarquera également qu'Appien précise que les "fameux" brigands contre lesquels Brutus a combattu habitaient non pas dans des repères isolés situés en montagne, mais dans des villes, ce qui est peu conforme à l'image habituelle du brigand. Or, Appien considère, comme ses sources, que Rome se devait de détruire la plupart des villes indigènes qui n'étaient rien d'autre que des repères de brigands - puisque constituant autant de points de résistance à la conquête-, ou à tout le moins les fortifications qui les entouraient habituellement. Il s'agissait là de mesures de sûreté publique destinées à endiguer définitivement le problème de l'insécurité dans les zones

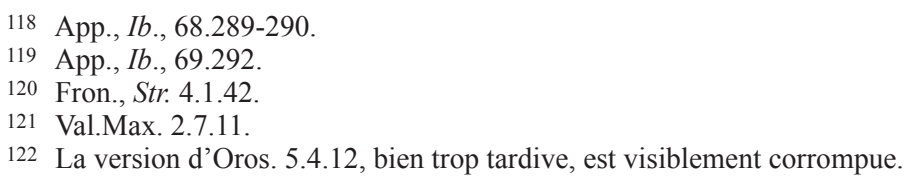


passées sous le contrôle de l'Urbs. Tout en reconnaissant que la conquête a donné lieu à des exactions sans nom, Appien tente ainsi de justifier les mesures prises en montrant à ses lecteurs que sans elles le pays tout entier n'aurait pas pu profiter des bienfaits de la conquête et de la civilisation. Il va sans dire que dans son esprit, la destruction des villes devait nécessairement se combiner avec l'instauration de mesures de distribution de terres destinées à offrir aux habitants de nouvelles zones où s'installer sous le contrôle des autorités romaines. ${ }^{123} \mathrm{Il}$ ne pouvait être question, comme cela semble avoir été le cas dans les premiers temps de la conquête, de se contenter de détruire les villes, c'est-à-dire les points de résistance, sans proposer aux indigènes de les réinstaller ailleurs, dans des zones et sur des terres contrôlées par Rome. C'est à n'en pas douter l'absence de ces mesures qui créa, en tout cas dans l'esprit d'Appien, les problèmes auxquels les autorités romaines furent très rapidement confrontées à partir du moment où elles commencèrent à s'imposer aux indigènes comme leurs nouveaux maîtres, c'est-à-dire dans les années comprises entre 206, date du départ des Carthaginois, et 197, date de la création des provinces de l'Hispania Citerior et de l'Hispania Ulterior.

La suite du récit d'Appien apporte des éléments venant confirmer la justesse de l'hypothèse défendue ici. C'est tout d'abord la nature du traité conclu entre Viriathe et Coepio, en 140. Quand Viriathe eut conclu la paix avec Rome à la suite d'un foedus aequum, qui ne sera pas respecté, bien qu'il ait été ratifié par le Peuple romain, ${ }^{124}$ et eut reçu le titre honorifique d'“ami du peuple romain", Rome décréta que tous ses partisans garderaient la terre qu'ils occupaient alors, plus exactement que tous ceux qui dépendaient de Viriathe "détenaient la souveraineté sur le territoire qu'ils possédaient". ${ }^{125}$ Autrement dit, Rome reconnaissait officiellement que le territoire occupé par les Lusitaniens leur appartenait bel et bien. Elle était disposée à respecter dans le présent comme dans l'avenir l'intégrité territoriale et l'autonomie politique de ce peuple. Il s'agit assurément là d'un acte de grande portée politique. Alors que depuis 206, une portion importante du territoire de l'Hispania est considérée comme faisant désormais partie intégrante de l'Empire de Rome, et que la conquête vient régulièrement agrandir l'espace contrôlé par l'Urbs, les Lusitaniens, parmi tous les peuples de la péninsule, sont les seuls à se voir reconnaître la possibilité insigne de garder leur territoire. Car contrairement aux capitulations précédentes qui mettaient en présence des Hispani et des Romains, comme par exemple lors de la capitulation des Numantins face à Pompée, ${ }^{126}$ ici, ce sont exceptionnellement les Romains qui se retrouvent dans le rôle peu glorieux du vaincu. On comprend dès lors la réaction de Caepio, le signataire de l'accord, qui selon Appien “décriait le traité, écrivant à Rome qu'il n'y en avait pas de plus honteux". ${ }^{127}$ Pour une puissance hégémonique comme l'était Rome,

123 Voir dans le même sens, Ciprés 1993, 156-159. Je me désolidarise toutefois de l'auteur quand elle semble en effet accréditer l'idée selon laquelle les Lusitaniens qui luttèrent contre Rome étaient bien des bandits (158). Sur l'importance stratégique de la ville, voir, entre autres, CADIOU 2008, 51-59.

124 App., Ib., 69.295; 70.296-298; voir De Sanctis 1964: 230; Goukowsky 2003, 63, n. 393; Pastor MuÑoz 2008, 44.

125 App., Ib., 69.295.

126 App., Ib., 79.340-341.

127 App., Ib., 70.296. 
il ne pouvait, en effet, rien y avoir de plus honteux que le fait de s'avouer vaincu par un petit peuple barbare des confins de l'Hispania. Diodore parle d'un "traité indigne des Romains". ${ }^{128}$

Compte tenu de ce que nous dit Appien des termes du traité, il ne pouvait être question de distribution de terres pour cause de pauvreté. Rome n'a pas distribué de terres aux Lusitaniens. Elle a en revanche reconnu le droit des Lusitaniens à disposer de leurs terres comme bon leur semblait. Rien dans ce passage ne permet d'accréditer l'hypothèse selon laquelle la résolution du problème lusitanien passait nécessairement par une redistribution de la terre qui était passée depuis le début de la conquête sous l'autorité de Rome.

\section{Les raisons du choix du thème de la faim de terres chez Appien}

Pourquoi Appien a-t-il privilégié le thème de la faim de terres pour tenter d'expliquer les guerres lusitaniennes? La conclusion de ce long conflit, en 139, telle qu'elle nous est rapportée par l'auteur, met en effet de nouveau en exergue le fait que la terre aurait constitué dès l'origine son enjeu majeur:

Repoussés de cette région [Sédétanie ou Édétanie], ils cherchaient à franchir le fleuve Bétis, serrés de près par Cæpio. À la fin, n'en pouvant plus, Tautalos livra sa personne et son armée à Cæpio, afin qu'il les traitât en sujets de Rome. Ce dernier leur enleva toutes leurs armes et leur donna assez de terres pour qu'ils ne se livrassent plus au brigandage par manque de ressources. ${ }^{129}$

La version des mêmes faits rapportés par Diodore diffère beaucoup de celle d'Appien. Contrairement à ce dernier, l'historien de Sicile met clairement en avant la volonté de Rome de contrôler les indigènes à travers les fondations de villes:

Le général romain frappa de terreur Tautamus, successeur de Viriathe, ainsi que ses partisans, leur imposa un traité, et leur donna un territoire et une ville, où ils devaient s'établir. ${ }^{130}$

Pour Diodore, cette distribution de terres relevait de la politique habituelle de Rome. Il n'y a là aucune mesure "sociale" destinée à aider les Lusitaniens. Rien dans le texte de Diodore ne permet d'accréditer l'idée que les Lusitaniens auraient pu recevoir de la terre pour mettre fin à leur brigandage par manque de ressources.

Il en va de même du célèbre passage de Strabon (3.3.5) dans lequel l'auteur décrit la situation des Ibères et la manière dont Rome a procédé pour les soumettre et leur apporter, malgré eux, la civilisation. En réduisant les villes à de simples bourgs, et en leur imposant des colonies de peuplement sur leur ancien territoire, les Romains cherchaient à réduire au maximum leur possibilité de réaction et à les surveiller au plus

128 D.S. 33.fr. 1.

129 App., Ib., 75.321.

130 D.S. 33.1.4. 
près. Aussi, aux dires de Strabon, et contrairement à certaines assertions d'Appien, ce n'est donc pas la pauvreté du territoire qui poussa les Hispani à privilégier la guerre et le brigandage au détriment des travaux agricoles ou artisanaux, mais l'amour de la guerre. Plutarque ne dit pas autre chose quand il évoque la nomination de Marius en Espagne (Propréteur en Lusitanie, en 114). ${ }^{131}$

Au-delà du regard critique qu'il convient absolument de poser sur les propos de Strabon et de Plutarque, qui ne font que nous enfermer dans le topos du caractère indompté des Hispani et de leur propension à se livrer au brigandage, on ne peut que constater qu'Appien est, de tous les auteurs antiques, le seul à avoir autant insisté sur le problème de la terre et sur la pauvreté des indigènes acculés à se livrer au brigandage pour survivre. Son récit des guerres lusitaniennes est du reste le seul de tous les récits de l'Ibérique où l'auteur fait explicitement mention de brigands et de faits de brigandage. On ne trouve qu'une seule autre mention de brigands à l'occasion d'un épisode de la guerre de Numance, de l'an 141, sous le consulat de Q. Pompeius. Appien y dépeint la détermination des indigènes à faire face à l'adversité et à la mort. Aussi ne cache-t-il pas son admiration pour ces hommes et ces femmes qui n'hésitaient pas à se donner la mort plutôt que de subir la servitude. ${ }^{132}$

Localisé essentiellement dans le centre et le sud-sud-ouest (principal théâtre des opérations de la décennie 149-139) de la péninsule, le brigandage semble, aux dires d'Appien, le fait de populations arriérées, qui n'ont pas eu de contact avec Rome ou qui venaient d'entrer en contact avec la civilisation romaine au moment du déclenchement des guerres indigènes, au début du II siècle avant J.-C. ${ }^{133}$ Appien a cru comprendre que le brigandage était provoqué par des problèmes économiques. À sa suite, les modernes ont interprété les textes antiques à l'aune de l'idée qu'il s'était fait des causes des guerres indigènes. Or, comme l'a proposé M. V. García Quintela, la causalité économique mise en avant par Appien, Diodore ou Strabon, doit être, a priori, recherchée dans l'œuvre de Poseidonios. L'auteur reconnaît qu'il n'existe pas de preuve univoque pour étayer son hypothèse. Il relève cependant un certain nombre de faits convergents qui laissent à penser que l'œuvre de Poseidonios a pu être à l'origine de cette interprétation des faits de la péninsule Ibérique: “a) Diodore le suit apparemment directement dans ces passages où sont évoquées la misère et la faim de terres comme cause du banditisme; b) Strabon dépend de lui dans certains passages-clés que nous avons étudiés dans le même sens; c) comme nous l'avons vu, Appien insiste sur la mention de la faim de terres dans la deuxième moitié du II siècle, or ce serait précisément la période que Poseidonios couvre avec le plus de détails dans son œuvre historique; d) dans certains textes, nous apprécions un soin particulier dans l'utilisation d'un vocabulaire d'analyse politique, qui est en accord avec des catégories clairement hellénistiques; e) enfin, la dynamique des cités grecques est décrite, dans l'historiographie et la sociologie hellénistiques, en termes d'affrontements entre riches et pauvres. Ainsi, puisque la description des faits de la deuxième moitié du $\mathrm{II}^{\mathrm{e}}$ siècle se présente comme une adaptation de ces catégories et un reflet de

131 Plu., Marius, 6.2 (trad. Anne-Marie Ozanam, Paris, 2001).

132 App., $I b ., 77.331$.

133 Gómez Fraile 2005, 125-144. 
ce type d'analyse, nous devons considérer que c'est Poseidonios qui les a introduits pour expliquer les faits de la Péninsule". ${ }^{134}$ L'hypothèse de García Quintela est parfaitement plausible et, en tout cas, d'une portée heuristique supérieure comparée aux thèses avancées depuis la fin du XIX ${ }^{\mathrm{e}}$ siècle qui ne font, en réalité, que perpétuer les stéréotypes de l'idéologie gréco-latine.

Si Diodore et Tite-Live ont défendu l'idée d'une hégémonie romaine triomphale, Appien, pour sa part, paraît bien plus attentif au devenir de l'Empire et aux événements qui ont pu entacher son image. Si par ailleurs Appien a utilisé, non pas Polybe ou Diodore mais des historiens romains, comme cela semble acquis, ${ }^{135}$ il a visiblement procédé, pour les besoins de sa démonstration, à un tri dans l'information recueillie. Il a réservé les allusions au brigandage à un moment clé de sa narration, plus précisément aux événements qui opposèrent Rome aux populations d'Hispania Ulterior, entre 155 et 139. C'est, en effet, à l'occasion des guerres lusitaniennes qu'Appien emploie de manière presque systématique le terme lèstès pour qualifier les adversaires de Rome. La narration des guerres lusitaniennes s'insère ainsi dans le développement global de l'Ibérique, mais selon une progression thématique et non pas chronologique comme on aurait pu logiquement s'y attendre. ${ }^{136} \mathrm{Ce}$ faisant, il distingue nettement quatre grandes guerres, pouvant se décliner respectivement en différentes phases d'opérations militaires. À chaque guerre correspond dans l'esprit d'Appien une sorte de "morale". Préoccupé par le devenir de Rome et de son image, sans doute aussi influencé par "l'idéologie de la pax romana", ${ }^{137}$ Appien, auteur peu fiable, s'est servi des différentes guerres menées par Rome en Hispania pour illustrer, à partir de quelques d'exemples emblématiques, la manière dont il a été possible, par le bon vouloir de quelques hommes, soit de gérer rationnellement et efficacement la conquête, soit au contraire de provoquer le mécontentement des indigènes et de s'enliser dans une suite sans fin de conflits particulièrement meurtriers. Une présentation purement chronologique des faits, comme a pu le faire Tite-Live, ne lui aurait pas permis de stigmatiser de la sorte le comportement de certains généraux romains ayant commandé en Espagne. Chaque guerre peut ainsi être qualifiée d'exemplaire d'un comportement particulier. On peut dès lors supposer qu'Appien a tenté de justifier, par le recours quasi systématique à la problématique du brigandage, les choix stratégiques de généraux romains particulièrement cupides et par-dessous tout préoccupés par la recherche de la gloire. Le thème du brigand lusitanien lui a ainsi offert la possibilité de légitimer la violence de la conquête romaine. Appliquant une grille de lecture qu'il a vraisemblablement empruntée à Poseidonios, Appien faisait ainsi d'une pierre deux coups: d'une part, il suggérait que les causes de ces guerres devaient être recherchées dans les contradictions internes aux sociétés indigènes et d'autre part, que la réaction des généraux romains, même excessive, se justifiait puisqu'ils avaient eu affaire à des brigands avec lesquels, comme chacun sait, il n'y a pas de possi-

134 García Quintela 1991, 95-96.

135 Voir Goukowsky 2003, XXXIX-XLIII; contra Rubinsohn 1981, 163 sq.

136 Sur le découpage thématique de la séquence chronologique relative aux guerres indigènes, voir Goukowsky 2003, XX-XXII; voir également Richardson 2000, 3-4.

137 García Quintela 1991, 94-95. 
bilité de traiter. ${ }^{138}$ Peut-être y avait-il aussi de la part d'Appien le désir de justifier les défaites subies par Rome en Hispania, non pas à cause de la qualité des troupes ennemies ou de leurs chefs, mais à cause de l'incompétence du leadership romain. Il faudra en effet attendre l'arrivée de C. Scipio AEmilianus, comme le laisse clairement entendre Florus (2.18), pour voir la résistance des Hispani rapidement écrasée. ${ }^{139}$

Appien aurait ainsi participé à l'instrumentalisation politique et idéologique de la conquête de l'Hispania. ${ }^{140}$ Il paraît en effet indéniable que pour l'historien d'Alexandrie, Rome, en luttant contre le banditisme, se donnait comme objectif de civiliser contre leur gré les populations de l'Hispania. Elle leur offrait ainsi la possibilité de rejeter cette vie méprisable qui consistait à ne pas exploiter les ressources naturelles du pays, mais à s'approprier par la force et la violence les fruits du labeur des voisins. ${ }^{141}$ Malgré le coût humain élevé des campagnes militaires et les réticences qui se faisaient jour ouvertement dans l'opinion publique romaine, ${ }^{142}$ il parait évident que Rome considéra qu'il était nécessaire de mener le processus de la conquête à son terme. Outre les richesses qu'elle en tirait, sans compter celles qui allaient enrichir directement les généraux romains, l'Urbs ne pouvait tolérer l'idée que les Hispani retombent dans la barbarie qui les caractérisait avant son arrivée et tout particulièrement dans le brigandage. ${ }^{143}$ Brigandage qui se faisait au détriment des peuples hispaniques alliés de Rome et qu'elle se devait de protéger.

\section{BiBLIOGRAPHIE}

AlarCão, J. DE (2001): "Novas perspectivas sobre os Lusitanos (e outros mundos)", RPA 4/2, 293-349.

Auliard, C.

(2005): "Les deditiones, entre capitulations et négociations", [en] M. Garrido-Hory - A. Gonzales (éd.), Histoire, espaces et marges de l'Antiquité. Hommage à Monique Clavel-Lévêque, Besançon, 255-270.

(2006): "Les magistrats et les deditiones aux IV et III ${ }^{\mathrm{e}}$ siècles, entre guerre et diplomatie", [en] E. Caire - S. Pittia (éd.), Guerre et diplomatie romaines (IV - III siècles av. J.-C.). Pour un réexamen des sources, Aix-en-Provence, 139-156.

138 Sur le brigand / bandit plus particulièrement dans l'Antiquité gréco-romaine, voir, parmi une abondante littérature, Steinmayer 1955-1956; Flam-Zuckermann 1970; Dyson 1975; Briant 1976; Clavel-Lévêque 1976; Clavel-Lévêque 1978; Shaw 1984; Dyson 1985, 207-208; Hobsbawm 1999; Shaw 2002; WolfF 2003; GRÜNEWALD 2004.

139 BANE 1976, 414.

140 VALlejo Girvés 1994, 167.

141 Bane 1976, 412-414; VAllejo Girvés 1994, 169.

142 Plb. 35.1-14; App., Ib., 49.209. Sur les problèmes de recrutement des tribuns et des légats militaires que provoqua la peur de servir en Hispania, voir TAYLOR 1962, 21-22; EARL 1963, 33; BRUNT 1971, 397-398; Shochat 1980, 56-57; Evans 1988, 124-125 et n. 27; García Moreno 1989, 25-26; ErdKamp 2006, 48-49.

143 BANE 1976, 412 et 414; VALLEJo GiRVÉs 1994, 170-171; sans se prononcer sur les raisons du banditisme, VALLEJo GIRVÉs 1994, 172, considère, en parfait accord avec l'hypothèse socio-économique défendue par GaRCía y Bellido, que l'existence même de ce phénomène "en diversas áreas peninsulares parece algo incuestionable o cuanto menos lógico y previsible, así como que el perjuicio económico, social, militar y político que causaba debía ser enorme". 
BAne, R. W. (1976): "The Development of Roman Imperial Attitudes and the Iberian Wars", Emerita 44/2, 409-420 (http://dx.doi.org/10.3989/emerita.1976.v44.i2.938).

BÉAL, J.-C. (1996): “Bibracte-Autun, ou le «transfert de capitale»: lieu-commun et réalités archéologiques", Latomus 55, 339-356.

Beltrán Lloris, F. (1988): “Un espejismo historiográfico. Las «organizaciones gentilicias» hispanas", [en] G. Pereira Menaut (ed.), Actas $1^{\text {er }}$ Congreso Peninsular de Historia Antigua, Santiago de Compostela, 197-237.

BlÁzquez, J. Ma (1974): Ciclos y temas de la historia de España. La romanización. 1, Madrid.

BRIANT, P. (1976): “«Brigandage», dissidence et conquête en Asie achéménide et hellénistique", DHA 2/1, 163-258.

Brunt, P. A. (1971): Italian Manpower, 225 B.C. - A.D. 14, Oxford.

CAdiou, F. (2008): Hibera in Terra Miles. Les armées romaines et la conquête de l'Hispanie sous la République (218 - 45 av. J.-C.), (=Bibliothèque de la Casa de Velázquez 38), Madrid.

Cadiou, F. - Magallón Botaya, Ma Á. - Navarro Caballero, M. (Éd.), (2008): La guerre et ses traces dans la péninsule Ibérique à l'époque de la conquête romaine: approches méthodologiques, Zaragoza-Bordeaux.

CAdiou, F. - Navarro CABAllero, M. (ÉD.), (2014): La guerre et ses traces. Conflits et sociétés en Hispanie à l'époque de la conquête romaine (III ${ }^{e}-I^{e r}$ a.C.), (=Ausonius Éditions, Collection Mémoires 37), Bordeaux.

Caro Baroja, J. (2003) [1946]: Los pueblos de España, 1 (=El Libro de bolsillo. Antropología), Madrid.

CArriÈre, J.-C. (1981): Pirates, brigands et empires. Le pillage et la pacification de la Méditerranée antique. Choix de textes grecs et latins (=Suppl. au Bulletin de l'Association régionale des enseignants de langues anciennes de l'Académie de Besançon 5417), Besançon.

Chic García, G. (1980): “Consideraciones sobre las incursiones lusitanas en Andalucía”, Gades 5, 15-25.

CIPRÉs, P. (1993): Guerra y sociedad en la Hispania indoeuropea (=Anejos de Veleia, Series Minor 3), Vitoria-Gasteiz.

Clavel-LévêQue, $\mathrm{M}$.

(1976): “À propos des brigands: discours, conduites et pratiques impérialistes”, DHA 2/1, 259-262.

(1978): "Brigandage et piraterie: représentations idéologiques et pratiques impérialistes au dernier siècle de la République", $D H A$ 4/1, 17-31.

CosTA, J. (1891-1895): “Cuatrería ó abigeato”, [en] Estudios ibéricos, Madrid, XXXIX-LIV.

De Sanctis, G. (1964): Storia dei romani. IV, La fondazione dell'impero. Parte III. Alla battaglia di Pidna alla caduta di Numanzia (=Il pensiero storico 38, VIII), Firenze.

Domínguez Monedero, A. J. (1986): "La campaña de Aníbal contra los Vacceos: sus objetivos y su relación con el inicio de la segunda guerra púnica”, Latomus 45/2, 241-258.

Dyson, S. L.

(1975): "Native Revolt Patterns in the Roman Empire", ANRW II/3, 138-175.

(1985): The Creation of the Roman Frontier, Princeton. 
Earl, D. C. (1963): Tiberius Gracchus. A Study in Politics (=Collection Latomus 66), Bruxelles-Berchem.

ERdKamp, P. (2006): "The Transformation of the Roman Army in the Second Century B.C.", [en] Ñaco - Arrayás (eds.), 2006, 41-51.

Étienne, R. (1958): Le culte imperial dans la Péninsule ibérique d'Auguste à Dioclétien, Paris.

Evans, J. K. (1988): "Resistance at home: the evasion of military service in Italy during the second century B.C.", [en] T. Yuge - M. Doi (eds.), Forms of control and subordination in Antiquity, Tokyo-Leiden, 121-140.

Ferrary, J.-L. (1988): Philhellénisme et impérialisme. Aspects idéologiques de la conquête romaine du monde hellénistique, de la seconde guerre de Macédoine à la guerre contre Mithridate (=Bibliothèque des Écoles françaises d'Athènes et de Rome 271), Rome.

Flam-ZuckermanN, L. (1970): “À propos d'une inscription de Suisse (CIL, XIII, 5010): étude du phénomène du brigandage dans l'Empire romain", Latomus XXIX, 451-473.

FrançoIs, P. (2003): "Notice", [en] Tite-Live. Histoire romaine. Tome XIX. Livre XXIX (=Coll. des universités de France), Paris.

García Moreno, L. A.

(1987): "Presupuestos ideológicos de la actuación de Roma durante el proceso de la conquista de Hispania", Gerión 5, 211-243.

(1988): “Hispaniae Tumultus. Rebelión y violencia indígena en la España romana de época republicana", Polis 1, 81-108.

(1989): "La Hispania anterior a nuestra era: verdad, ficción y prejuicio en la historiografía antigua y moderna", [en] Actas del VII Congreso Español de Estudios Clásicos, Madrid, 17-46.

(1993): “Organización sociopolítica de los Celtas en la Península Ibérica”, [en] M. Almagro-Gorbea - G. Ruiz Zapatero (eds.), Los Celtas: Hispania y Europa, Madrid, 327-355.

García Quintela, M. V.

(1990): “Les peuples indigènes et la conquête romaine de l'Hispanie. Essai de critique historiographique", DHA 16/2, 181-210.

(1991): "Sources pour l'étude de la Protohistoire d'Hispanie. Pour une nouvelle lecture", DHA 17/1, 61-99.

GARcía RiazA, E.

(2002): Celtíberos y Lusitanos frente a Roma: diplomacia y derecho de guerra, Vitoria.

(2011): De fronteras a provincias. Interacción e integración en Occidente (ss. III-I a.C.), Palma.

García y Bellido, A. (1945): “Bandas y guerrillas en las luchas con Roma”, Hispania V/XXI, 549-604.

Gómez Fraile, J. M

(1999): "Mercenariado y bandolerismo en Celtiberia. Dos cuestiones desenfocadas", [en] F. Burillo Mozota (ed.), IV Simposio sobre Celtiberos. Economía. Homenaje a José Luis Argente Oliver (Daroca, Zaragoza, 25-27 de septiembre de 1997), Zaragoza, 503-509.

(2005): "Precisiones sobre el escenario geográfico de las guerras lusitanas (155-136 A.C.). A propósito de la presencia de Viriato en Carpetania", Habis 36, 125-144.

Goukowsky, P. (2003): “Notice”, [en] Appien. Histoire romaine. Tome II. Livre VI. L'Ibérique (=Collection des universités de France), Paris. 
Gozalbes Cravioto, E. (2006): “Algunos modelos de interpretación del bandolerismo hispano en la Antigüedad", [en] S. Castillo - P. Oliver Olmo (coords.), Las figuras del desorden: heterodoxos, proscritos y marginados, Madrid, 1-17.

Grünewald, T. (2004): Bandits in the Roman Empire. Myth and Reality, London-New York. Harris, W. V. (1989): War and Imperialism in Republican Rome, 327-70 B.C., Oxford.

Hobsbawm, E. J. (1999): Les bandits (=Collection Poche), Paris.

KnApp, R. C. (1980): “Cato in Spain, 195/194 BC", [en] C. Deroux (ed.), Studies in Latin literature and Roman history (=Collection Latomus 168), Bruxelles, 21-56.

López Melero, R. - Salas Martín, J. - Sánchez Abal, J. L. - García Jiménez, S. (1984): “El Bronce de Alcántara. Una deditio del 104 a.C.”, Gerión 2, 265-324.

Miguel y Ayala, M. DE (2002): "Los honderos Baleares: mercenarios en las filas de las legiones romanas", [en] A. Morillo Cerdán (ed.), Arqueología militar romana en Hispania (=Gladius 5), Madrid, 529-535.

ÑACO, T. - ARrayÁs, I. (EDS.), (2006): War and Territory in the Roman World (Guerra y territorio en el mundo romano), (=BAR International Series 1530), Oxford.

PASTOR MuÑoz, M.

(2000): "La figura de Viriato y su importancia en la sociedad lusitana", [en] J.-G. Gorges - T. Nogales Basarrate (eds.), Sociedad y cultura en Lusitania romana. IV Mesa Redonda Internacional (=Serie Estudios Portugueses 13), Mérida-Madrid, 35-52. (2008): Viriate. La lutte pour la liberté, Paris.

Pena, M. J. (1994): “Conquête et colonisation dans la Péninsule ibérique pendant le II siècle av. n.è.", [en] M. Clavel-Lévêque - I. Jouffroy - A. Vignot (éd.), De la terre au ciel. I. Paysages et cadastres antiques (=Centre de Recherche d'Histoire ancienne 136. Espaces et paysages 3), Besançon, 247-258.

Pina Polo, F. (2006): "Imperialismo y estrategia militar en la conquista de Hispania citerior (218-153 a.C.)", [en] F. Burillo Mozota (ed.), Segeda y su contexto histórico: entre Catón y Nobilior (195 al 153 a.C.). Homenaje a Antonio Beltrán Martínez (=Estudios celtibéri$\cos 2)$, Mara, 71-80.

Quesada SAnz, F.

(2006): “Los Celtíberos y la guerra: tácticas, cuerpos, efectivos y bajas. Un análisis a partir de la campaña del 153", [en] F. Burillo Mozota (ed.), Segeda y su contexto histórico. Entre Catón y Nobilior (195 al 153 a.C.). Homenaje a Antonio Beltrán Martinez (=Estudios celtibéricos 2), Mara, 149-167.

(2006a): "Not so different: individual fighting techniques and small unit tactics of Roman and Iberian armies within the framework of warfare in the Hellenistic Age", [en] P. François et alii, L'Hellénisation en Méditerranée occidentale au temps des guerres puniques (260-180 av. J.-C.), (=Pallas 70), Toulouse, 245-263.

Quesada Sanz, F. - Navarro Caballero, M. - Cadiou, F. (Coords.), (2010): De armas, de hombres y de dioses. El papel de las armas en la conquista romana de la Península Ibérica (=Gladius 30), 2010.

Richardson, J. S. (2000): “Introduction” \& “Commentary”, [en] Appian. Wars of the Romans in Iberia (=Classical texts), Warminster.

Rubinsohn, Z. W. (1981): “The Viriatic war and its Roman repercussions”, RSA 11, 161-205. 
SALINAS DE FRÍAs, M.

(1982): La organización tribal de los vettones (Pueblos prerromanos de Salamanca) (=Temas de historia local y provincial. Serie varia 15$)$, Salamanca.

(2008): "La jefatura de Viriato y las sociedades del occidente de la Península Ibérica", Palaeohispanica 8, 89-120.

SÁnChEz Corriendo, J. (1997): “Bandidos lusitanos o pastores trashumantes?”, HAnt 21, 123154.

SÁNCHEZ Moreno, E.

(2006): "Ex pastore latro, ex latrone dux. Medioambiente, guerra y poder en el occidente de Iberia", [en] Naco - Arrayás (eds.), 2006, 55-79.

(2011): "De la resistencia a la negociación: acerca de las actitudes y capacidades de las comunidades hispanas frente al imperialismo romano", [en] E. García Riaza (ed.), De fronteras a provincias. Interacción e integración en Occidente (ss. III-I a.C.), Palma de Mallorca, 97-103.

Santos Yanguas, N. (1981): "Las incursiones de Lusitanos en Hispania Ulterior durante el siglo II A.N.E.", Bracara Augusta 35, 355-366.

Santos Yanguas, N. - Montero Honorato, Ma Del P. (1982): “Los Celtíberos, mercenarios de otras poblaciones ibéricas", Celtiberia XXXII/63, 5-16.

Sayas Abengochea, J. J. (1988): "El bandolerismo lusitano y la falta de tierras", [en] Homenaje al profesor Antonio de Bethéncourt y Massieu (=ETF, Serie IV, $\mathrm{H}^{\mathrm{a}}$ Moderna 1), Madrid, 701-714 (http://dx.doi.org/10.5944/etfiv.1.1988.3204).

Schulten, A.

(1914): Numantia. Die Keltiberer und ihre Kriege mit Rom, I, München.

(1935): Fontes hispaniae antiquae. III, Las guerras de 237 - 154 a. de J. C., Barcelona.

SHAW, B. D.

(1984): "Bandits in the Roman Empire", $P \& P$ 105, 3-52 (http://dx.doi.org/10.1093/ past/105.1.3).

(2002): "Le bandit", [en] A. Giardina (dir.), L’homme romain (=Points Histoire 305), Paris, $385-435$.

Sноснат, Y. (1980): Recruitment and the programme of Tiberius Gracchus (=Collection Latomus 169), Bruxelles.

Steinmayer, G. (1955-1956): "Sviluppi semantici della base «latro» in Grecia e in Roma”, [en] Atti e memorie dell'Accademia d'agricoltura, scienze e lettere di Verona, Verona, 151-163.

TAYlOR, L. R. (1962): "Forerunners of the Gracchi", JRS 52, 19-27 (http://dx.doi. org/10.2307/297874).

Tovar Llorente, A. (1989): Iberische Landeskunde. Segunda parte, Las tribus y las ciudades de la antigua Hispania. Tomo 3, Tarraconenses, Baden-Baden.

VAllejo GiRvés, M. (1994): “El recurso de Roma al bandidaje hispano", ETF, Serie II, $H^{a}$ Antigua 7, 165-173 (http://dx.doi.org/10.5944/etfii.7.1994.4238).

Wolff, C. (2003): Les brigands en Orient sous le Haut-Empire romain (=Collection de l'École française de Rome 308), Rome. 